\title{
Fitossociologia dos componentes lenhoso e herbáceo em uma área de caatinga no Cariri Paraibano, PB, Brasil ${ }^{1}$
}

\author{
Dacira R. Lima ${ }^{2,6}$, Rômulo G. da Silva ${ }^{3}$, Maysa P. Tomé3, Eduardo P. de Sousa Neto ${ }^{3}$, Rubens T. Queiroz ${ }^{4}$, \\ Mário Sérgio D. Branco ${ }^{5}$ e Marcelo F. Moro ${ }^{5}$
}

Recebido: 20 agosto 2018; aceito: 23 julho 2019

Como citar: Lima, J.R., Silva, R.G., Tomé, M.P., Sousa Neto, Queiroz, R.T., Branco, M.S.D. \& Moro, M.F. 2019. Fitossociologia dos componentes lenhoso e herbáceo em uma área de caatinga no Cariri Paraibano, PB, Brasil. Hoehnea 46: e792018. http://dx.doi.org/10.1590/2236-8906-79/2018.

ABSTRACT - (Phytosociology of the woody and herbaceous plant assemblages in an area of caatinga in Paraíba State, Brazil). The caatinga sensu stricto is a typical vegetation type of the Brazilian semiarid region and is adapted to strong seasonality in rainfall and high temperatures. It has a high species richness and a high level of beta diversity. The objective of this study was to document the flora and structure of woody and herbaceous plant assemblages of a site with caatinga vegetation. We sampled one hectare in the Reserva Particular do Patrimônio Natural Fazenda Almas (Paraíba State, Brazil). Our study recorded 114 species ( 34 woody/ 80 herbaceous), which is similar to other studies conducted in this vegetation type. The woody component presented density of 4822 ind.ha $^{-1}$ and a basal area of $38,851 \mathrm{~m}^{2}$.ha-1. For the herbaceous plants, we recorded variation in density, percentage of soil cover, and species richness between the dry and rainy seasons. Despite the high biodiversity, the caatinga still undergoes extensive environmental degradation processes. The present study documented the structure of a conserved tract of caatinga that can be a reference for future restoration projects.

Keywords: flora, herbaceous plant, phytogeographic domain of the caatinga, semiarid diversity

RESUMO - (Fitossociologia dos componentes lenhoso e herbáceo em uma área de caatinga no Cariri Paraibano, PB, Brasil). Caatinga sensu stricto é a vegetação típica do semiárido brasileiro, adaptada à forte sazonalidade das chuvas e às altas temperaturas. Possui alta riqueza de espécies e alto nível de diversidade beta. O objetivo do estudo foi documentar a flora e fitossociologia das plantas lenhosas e herbáceas de uma área de caatinga. Para isso, amostramos um hectare na Reserva Particular do Patrimônio Natural Fazenda Almas (Estado da Paraíba). A área apresentou diversidade florística de 114 espécies (34 lenhosas/ 80 herbáceas), semelhante a outros estudos realizados nessa vegetação. O componente lenhoso apresentou densidade absoluta de 4822 ind.ha- ${ }^{-1}$ érea basal de $38,851 \mathrm{~m}^{2} . \mathrm{ha}^{-1}$. Para plantas herbáceas foi registrada uma variação na densidade, percentual de cobertura do solo e riqueza de espécies entre as estações seca e chuvosa. Apesar da alta biodiversidade, a caatinga continua passando por extensos processos de degradação ambiental. O presente trabalho documentou a estrutura de um trecho conservado de caatinga que pode ser uma referência para futuros projetos de restauração. Palavras-chave: domínio fitogeográfico da caatinga, flora, planta herbácea, diversidade do semiárido

\section{Introdução}

O Domínio Fitogeográfico da Caatinga (DFC), localizado na região Nordeste do Brasil e no norte do Estado de Minas Gerais, ocupa área de aproximadamente $844,453 \mathrm{~km}^{2}$ (IBGE 2004), sendo considerada uma das maiores regiões semiáridas do mundo (Ab'Sáber 1977, Olson et al. 2001). É caracterizado por forte sazonalidade da precipitação (6 a 11 meses secos por ano), baixa precipitação (menor que $1000 \mathrm{~mm}^{-1}$.ano) e elevadas temperaturas durante todo o ano (Nimer 1989, Prado 2003, Sampaio 1995, 2003). Devido à sua grande extensão, essa região apresenta alta heterogeneidade climática,

1. Parte do Trabalho de Conclusão de Curso do segundo Autor

2. Universidade Federal Rural do Rio de Janeiro, BR-465, Km 7, S/N, 23851-970 Seropédica, RJ, Brasil

3. Universidade Federal de Campina Grande, Rua Jario Feitosa, 1770, Pereiro, 58840-000 Pombal, PB, Brasil

4. Universidade Federal da Paraíba, Campus I, Lot. Cidade Universitária, 58051-900 João Pessoa, PB, Brasil

5. Universidade Federal do Ceará, Instituto de Ciências do Mar, Avenida da Abolição, 3207, Meireles, 60165-081 Fortaleza, CE, Brasil

6. Autor para correspondência: jacirarabelo@gmail.com 
pedológica e geomorfológica (Ab'Sáber 2003, Andrade-Lima 1981), resultando na presença de diferentes tipos vegetacionais no seu Domínio. Entre esses tipos vegetacionais, destaca-se a caatinga sensu stricto (chamada neste trabalho apenas de caatinga), vegetação arbórea-arbustiva, caducifólia e espinhosa, que ocorre em áreas de baixas altitudes da região semiárida brasileira (até 500 metros).

A fitofisionomia e flora da caatinga são bastante variadas. Fisionomicamente, a caatinga pode apresentar padrão tanto arbustivo quanto arbóreo, podendo atingir até um porte florestal (Rizzini 1979, Moro et al 2016). A flora é representada por cerca de 4657 espécies, das quais pelo menos 913 são endêmicas (BFG 2015), sendo observada elevada proporção de espécies herbáceas, embora este componente seja comumente negligenciado em trabalhos realizados nessa vegetação (Moro et al. 2015). As famílias Leguminosae, Poaceae, Asteraceae e Euphorbiaceae estão entre as mais diversas na caatinga (BFG 2015, Queiroz et al. 2015, Ferraz et al. 2013, Araújo et al. 2012, Oliveira et al. 2009, Rodal et al. 2008, Giulietti \& Queiroz 2006, Queiroz 2006).

Estudos biogeográficos mostram que há evidências de que as comunidades vegetais se distribuem no DFC a partir dos diferentes setores geomorfológicos (Moro et al. 2016) e também seguindo gradientes climáticos de aridez (Silva \& Souza 2018), permitindo a ocorrência de comunidades florísticas bastante distintas ao longo deste Domínio (Moro et al. 2016). Quando comparada a outras vegetações expostas a ambientes semiáridos, a caatinga pode ser considerada como uma das mais diversas do mundo (Silva 2003). Apesar disso, essa vegetação tem sofrido relevantes pressões antrópicas, levando à perda de biodiversidade da região. Dentre as pressões observadas, destacam-se o uso de madeiras como fonte de energia, a pecuária extensiva, o extrativismo insustentável e o desmatamento para expansão da agricultura (Francisco et al. 2014, MMA 2007, Leal et al. 2005). Essas atividades podem reduzir ou mesmo eliminar populações de espécies nativas, levando ao empobrecimento ambiental dessa vegetação (Leal et al. 2005, Giulietti et al. 2004). Atualmente, o DFC já perdeu metade de sua cobertura vegetal original e sofre também com a fragmentação derivada da supressão da vegetação e da construção de estradas (Antogiovanni et al. 2018).

Em uma análise geográfica extensa sobre o desmatamento e fragmentação no DFC, Antogiovanni et al. (2018) mostraram que o setor leste deste Domínio é o mais fragmentado. Isso decorre do processo de colonização que começou na região costeira e migrou paulatinamente para o interior do continente, na transição entre os Domínios da Mata Atlântica e da Caatinga, chamada de "agreste" (Moro et al. 2016), e posteriormente nas áreas além do agreste, que são as áreas do leste do DFC, atualmente mais fragmentadas pela ação humana (Antogiovanni et al. 2018), justamente no contexto geográfico onde se localiza a presente área de estudos. Segundo o MMA (2010), o Estado da Paraíba é considerado como um dos estados que menos protege a vegetação de caatinga em Unidades de Conservação (UCs), apesar de $92 \%$ do seu território ser coberto por esse Domínio Fitogeográfico. Esse fato é preocupante, pois além das pressões antrópicas já destacadas, o Estado possui umas das áreas mais secas do Nordeste, o Cariri Paraibano (Barbosa et al. 2007, Simrppn 2014), localizado em um setor já bastante fragmentado do DFC (Antogiovanni et al. 2018). Assim, o uso inadequado do solo, associado ao clima extremamente seco, pode levar aos processos de desertificação (Francisco et al. 2014), que torna difícil a regeneração natural da vegetação em locais já bastante impactados pelo corte da vegetação, queimadas e sobrepastoreio (MMA 2015, Oliveira \& Sales 2015, Vieira et al. 2015).

O processo de desertificação é uma situação de degradação extrema (Oliveira \& Sales 2015) e, em paisagens que já estão muito fragmentadas, ações de recuperação ecológica proativas podem ser exigidas para recompor a vegetação e recuperar parte da biodiversidade original (Antogiovanni et al. 2018). Para projetos de restauração ecológica, entretanto, é preciso conhecer a composição e estrutura da vegetação típica da região para servir de referência a projetos de recomposição. Um aspecto que é negligenciado nos estudos fitossociológicos, entretanto, é a composição e estrutura das comunidades herbáceas. Enquanto as florestas tropicais pluviais são floristicamente dominadas por plantas lenhosas, formações abertas como caatinga, cerrado e pampas têm uma proporção muito maior de plantas herbáceas em sua flora, e maior proeminência do componente herbáceo na estrutura da vegetação (Costa et al. 2016, Moro et al. 2016, BFG 2015), de modo que uma efetiva recuperação da vegetação deveria idealmente levar em consideração ambos os componentes.

Desta forma, o estudo e a conservação do DFC é um grande desafio para a ciência brasileira, já que 
metade desse Domínio já foi alterado pelo homem (Antongiovanni et al. 2018, Castelletii et al. 2003, MMA 2015) e apenas cerca de 1\% do seu território está em UCs de proteção integral (MMA 2015, Tabarelli \& Vicente 2002, 2004). Assim, o conhecimento sobre a flora e estrutura fitossociológica poderá contribuir para a conservação e recuperação da caatinga (Sampaio 1996), tal como a presente no Cariri Paraibano (PB), que apesar de apresentar alto nível de degradação da vegetação natural, é considerada área de extrema importância para conservação (MMA 2002, 2007). Deste modo, o objetivo desse estudo foi conhecer a flora e estrutura dos componentes lenhoso e herbáceo em uma área de caatinga da Reserva Particular do Patrimônio Natural (RPPN) Fazenda Almas, localizada no Cariri Paraibano, estimar a riqueza total de espécies da área e compreender suas relações biogeográficas com outras áreas do DFC.

\section{Material e métodos}

Área de estudo - O trabalho foi realizado na RPPN Fazenda Almas ( $7^{\circ} 28^{\prime} 45^{\prime \prime}$ S e $\left.36^{\circ} 54^{\prime} 18^{\prime \prime} \mathrm{W}\right)$, situada no Planalto da Borborema, região do Cariri Paraibano (microrregião do Cariri ocidental), no município de São José dos Cordeiros, Paraíba (figura 1). A RPPN Fazenda Almas possui 3505 hectares, com altitude variando entre 580 e $740 \mathrm{~m}$ e solos derivados do embasamento de origem cristalina (Barbosa et al. 2015). O clima é do tipo tropical muito seco (Climatedata 2018), com a precipitação média anual de aproximadamente $630 \mathrm{~mm}$ e a média mensal em torno de $100 \mathrm{~mm}$ nos meses mais chuvosos (janeiro a maio) (Barbosa et al. 2015). A temperatura média anual é de $26^{\circ} \mathrm{C}$ (Barbosa et al. 2007, Barbosa et al. 2015), com temperatura média máxima de $30{ }^{\circ} \mathrm{C}$ e mínima em torno de $20^{\circ} \mathrm{C}$ (Climate-data 2018). Apesar da região apresentar alto nível de degradação da vegetação natural, a RPPN Fazenda Almas é uma das poucas áreas em bom estado de conservação na região, sendo considerada área prioritária para conservação do DFC (MMA 2002, 2007).

Composição e diversidade florística - Para o levantamento florístico foi selecionada uma área de um hectare (ha) em bom estado de conservação (mais de 50 anos sem corte da vegetação) no interior da RPPN Fazenda Almas. Foram realizadas coletas mensais no período de fevereiro de 2014 a junho de 2015. Todas as espécies (lenhosas e herbáceas) que estavam em estado reprodutivo (flor ou fruto) foram coletadas. A determinação botânica foi realizada com auxílio de chaves analíticas e por comparação com materiais depositados no Herbário JPB, já devidamente determinado por especialistas, ou ainda, através de material enviado a especialistas. O material botânico foi depositado no Herbário RBR, pertencente ao Departamento de Botânica da Universidade Federal Rural do Rio de Janeiro. As espécies foram classificadas em famílias, ordens e clados superiores segundo APG IV (2016). Espécies exóticas invasoras presentes na amostragem foram devidamente marcadas nas tabelas, a fim de destacar quais das espécies presentes na área não são nativas, conforme recomendado por Moro et al. (2012).

Com os dados obtidos foram calculados a riqueza de espécies, índice de diversidade de Shannon-Wiener $\left(\mathrm{H}^{\prime}\right)$ e a diversidade taxonômica $\left(\Delta^{+}\right)$(Magurran 2004) para os dois componentes analisados (lenhoso e herbáceo), usando o programa Past (Hammer et al. 2001). A principal premissa do $\Delta^{+}$é que a diversidade é maior em comunidades na qual as espécies são taxonomicamente mais distintas, ou seja, pertencem a diferentes táxons (ordens, famílias, gêneros).

Levantamento fitossociológico dos componentes lenhoso e herbáceo - Para o componente lenhoso, a parcela de um hectare $(100 \times 100 \mathrm{~m})$ foi subdividida em 100 subparcelas de $10 \times 10 \mathrm{~m}$. Todas as plantas lenhosas, excetos as trepadeiras, no interior das parcelas foram medidas em relação à altura total e perímetro no nível do solo (PNS). O critério de inclusão foi $\mathrm{PNS} \geq 9 \mathrm{~cm}$. Os seguintes parâmetros fitossociológicos foram calculados através do programa FITOPAC 2.1 (Sherpherd 2010): Número de Indivíduos (n), Densidade Absoluta (DAb), Densidade Relativa (DRe), Frequência Absoluta (FAb), Frequência Relativa (FRe), Dominância Absoluta (DoAb), Dominância Relativa (DoRe), Índice de Valor de Importância (IVI) e Índice de diversidade de Shannon-Weaner (H') (maiores detalhes em Rodal et al. 1992).

Das 100 subparcelas de $10 \times 10 \mathrm{~m}$ foram sorteadas 35 , no interior das quais foi realizado o levantamento fitossociológico das herbáceas. No centro de cada uma das 35 subparcelas sorteadas foi alocada uma parcela de $1 \times 1 \mathrm{~m}$ subdividida em 100 subparcelas de $10 \times 10 \mathrm{~cm}$. Quando o centro da subparcela de $10 \times 10$ mestava ocupado por uma árvore, a parcela de $1 \times 1 \mathrm{~m}$ era deslocada à esquerda dentro da mesma subparcela $(10 \times 10 \mathrm{~m})$. Considerando que a flora herbácea é efêmera e, em geral, desaparece nos períodos 


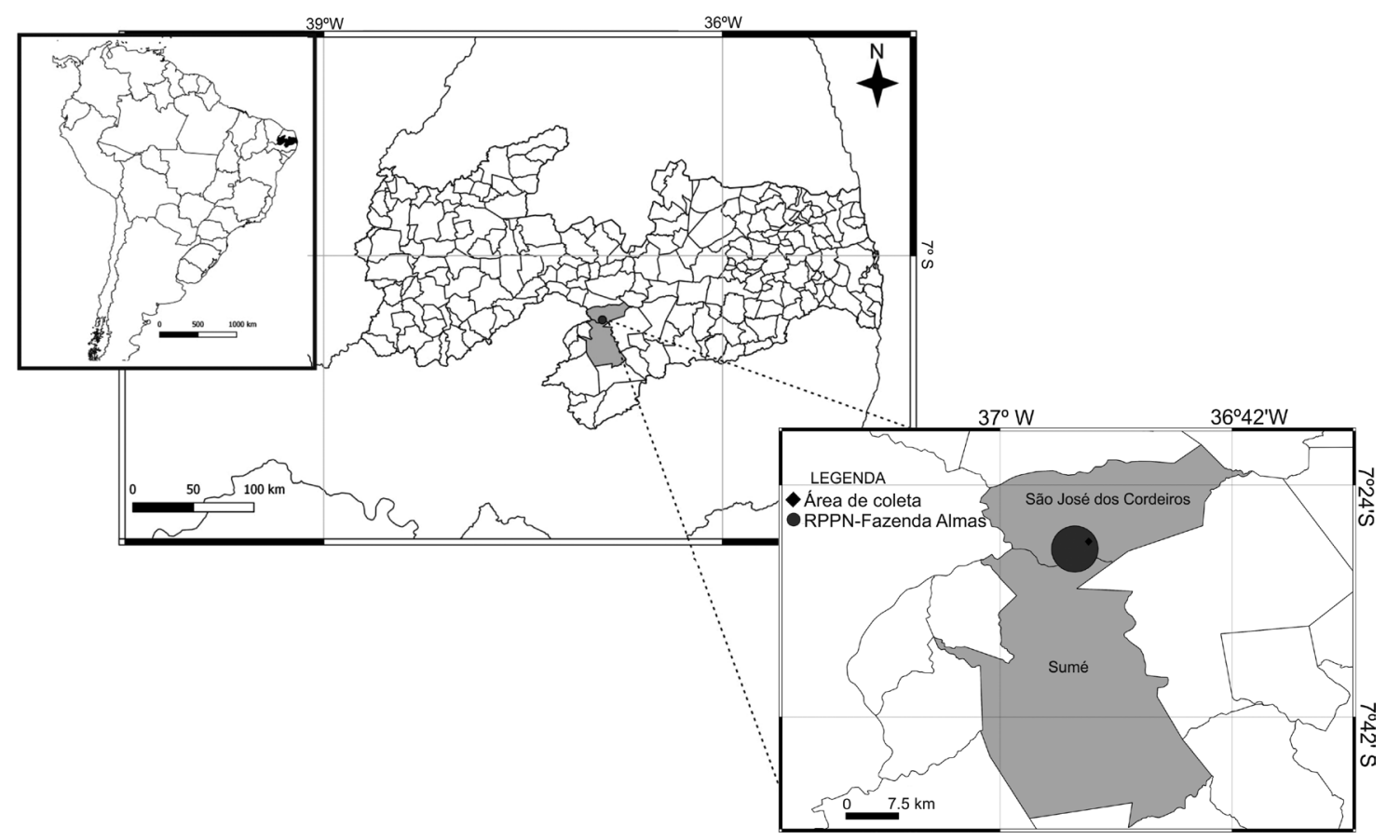

Figura 1. Mapa de localização da RPPN Fazenda Almas, no município de São José dos Cordeiros, Paraíba, Brasil.

Figure 1. Map of the location of the RPPN Fazenda Almas, in the municipality of São José dos Cordeiros, Paraíba State, Brazil.

mais secos, o componente herbáceo foi amostrado na estação chuvosa $\left(35 \mathrm{~m}^{2}\right.$ em março/2014) e na estação seca (mais $35 \mathrm{~m}^{2} \mathrm{em}$ setembro/2014), sendo usadas, nas duas estações, as mesmas subparcelas de $10 \times 10 \mathrm{~m}$, no interior das quais foram alocadas as parcelas de $1 \times 1 \mathrm{~m}$, aproximadamente na mesma posição. No presente estudo, as plantas herbáceas e subarbustivas foram consideradas como pertencentes ao componente herbáceo.

Os seguintes parâmetros foram calculados para as duas estações separadamente: número de indivíduos (n), densidade das espécies e famílias, riqueza de espécies, $\mathrm{H}^{\prime}, \Delta^{+}$e porcentagem de cobertura. A estimativa da porcentagem da cobertura foi realizada visualmente com o auxílio da parcela de $1 \times 1 \mathrm{~m}$, tendo como referência as subparcelas de $10 \times 10 \mathrm{~cm}$. Sempre que uma parte de uma planta herbácea estivesse presente em uma subparcela, era considerado que $1 \%$ da área estava coberta (Lima et al. 2011).

Rarefação, extrapolação e estimativa de riqueza total da flora - Para avaliar se a riqueza amostrada pelo levantamento fitossociológico era representativa da riqueza real da área, foram usados os métodos de rarefação (interpolação), extrapolação e estimativa de riqueza total (assintótica). Para isso, foi realizada a rarefação por parcelas da amostragem para avaliar a curva de acúmulo de espécies. Após essa etapa, a amostragem foi extrapolada para um tamanho três vezes maior que a amostragem real, para avaliar se era esperado um aumento considerável na riqueza registrada na área de estudos com um maior esforço amostral. Como toda amostragem em biodiversidade é tipicamente uma avaliação subestimada da riqueza total da área, para estimar o número total de espécies no local de estudos foi utilizado um grupo de estimadores estatísticos não-paramétricos que são baseados no número de espécies raras e na distribuição das espécies nas unidades amostrais. Esses algoritmos foram executados usando o software EstimateS 9.1.0 (Colwell \& Elsensohn, 2014) e estimam o número total de espécies em um determinado local a partir dos dados obtidos com as unidades amostrais (Gotelli \& Colwell 2011). Foram construídas curvas do coletor para o número de espécies observadas no presente estudo e para o número de espécies extrapoladas, caso o esforço amostral tivesse sido três vezes maior (Colwell et al. 2012). Também foram estimados o número total de espécies esperadas na área de estudo usando o ICE (estimador de cobertura baseado na incidência), Chao 2 e Jackknife 1 e 2 (Gotelli \& Colwell 2011).

Contextualização regional - Com o objetivo de compreender a relação florística entre a área de 
estudo com outras áreas do DFC, foram realizadas análises multivariadas de agrupamento e ordenação. Para isso foi utilizado o banco de dados "Caatinga", reunido por Moro et al. $(2014,2015,2016)$. Do banco de dados "Caatinga" foram selecionados apenas artigos que continham levantamentos da flora geral do local (componente herbáceo e lenhoso reportado no mesmo trabalho). Para tanto, foram extraídos 22 levantamentos, os quais abrangem os Estados do Ceará, Pernambuco, Paraíba e Piauí (tabela 1). Usando o software PAST 3.18 (Hammer et al. 2001), a matriz de presença-ausência de espécies nessas 22 áreas foi avaliada e foi calculado o índice de similaridade de Bray-Curtis entre cada par de áreas. Em seguida, a matriz de presença-ausência foi utilizada para analisar a semelhança florística entre os locais usando análise de agrupamento com o algoritmo UPGMA (Unweighted Pair-Group Method using Arithmetic Averages) e análise de ordenação utilizando NMDS (Non Metric Multidimensional Scaling) (Legendre \& Legendre 2012, McCune \& Grace 2002).

Acesso aos dados - As planilhas com os dados brutos de campo de fitossociologia, bem como a tabela da lista de espécies em formato digital e outras informações pertinentes estão disponíveis para os leitores no repositório Figshare através do link: https://doi.org/10.6084/m9.figshare.8111183.

\section{Resultados e Discussão}

Composição e diversidade florística da área estudada No hectare estudado foram registradas 114 espécies (34 espécies lenhosas e 80 herbáceas), pertencentes a 94 gêneros e 36 famílias (tabela 2). Foram registrados representantes de quatro divisões do Reino Plantae (Magnoliophyta, Marchantiophyta, Euphyllophyta e Lycopodiophyta), destacando-se angiospermas (Magnoliophyta), que representam aproximadamente $97 \%$ das espécies. A família mais rica foi Leguminosae (18 espécies), seguida por Euphorbiaceae (15) e Malvaceae (13). O componente herbáceo apresentou maior riqueza de espécies, $\Delta^{+}$e $\mathrm{H}^{\prime}$ (tabela 3 ).

A riqueza de espécies encontrada nesse estudo foi semelhante à média dos estudos florísticos realizados com plantas lenhosas e herbáceas em áreas de caatinga, que, segundo Moro et al. (2015) registram em média 106 espécies, embora existam trabalhos reportando de 25 até 250 espécies quando somados os componentes lenhoso e herbáceo. Moro et al. $(2014,2016)$ já haviam chamado a atenção sobre a maior riqueza florística da caatinga estar no componente herbáceo. Vegetações abertas como a caatinga e o cerrado têm uma elevada riqueza de plantas não lenhosas (BFG 2015), que acabam não sendo amostradas em muitos dos estudos florísticos (Moro et al. 2015).

A maior riqueza de espécies encontrada no componente herbáceo da área estudada parece ser uma resposta às variações climáticas, orográficas e edáficas (Sampaio 1995). Alguns estudos têm demonstrado que quanto menor a precipitação anual de uma área, maior é a proporção de espécies do componente herbáceo em relação ao lenhoso (Costa et al. 2007, Costa et al. 2016). Assim, estudos focados apenas nas plantas lenhosas acabam levando a uma subestimativa da diversidade florística local. Na região do Seridó, Estado do Rio Grande do Norte, levantamentos das plantas lenhosas levaram os botânicos a assumir que a região era muito pobre em espécies vegetais, com poucas espécies de árvores e arbustos registrados. Mas levantamentos focados também nas plantas herbáceas mostraram que a flora local é representada por mais de 300 espécies, sendo que a maior parte da diversidade está no componente herbáceo, e não no lenhoso (Queiroz et al. 2015). Assim, áreas de caatinga que historicamente eram consideradas pouco diversas, em muitos casos tinham apenas a maior parte da sua riqueza florística representada por plantas não lenhosas (Moro et al. 2016).

Vale destacar que o componente herbáceo da RPPN Fazenda Almas, além das angiospermas, também tem representantes de outras três divisões do Reino Plantae (Marchantiophyta, Euphyllophyta e Lycopodiophyta) não presentes no componente lenhoso, além de sete ordens exclusivas de angiospermas (Alismatales, Asparagales, Asterales, Commelinales, Dioscoriales, Oxalidales e Poales). Além disso, esse componente é floristicamente dinâmico, sendo observada uma variação na composição florística entre as estações, ou seja, é um componente sensível às variações climáticas tipicamente observadas nesse tipo de vegetação.

A maior riqueza das famílias Leguminosae (18) e Euphorbiaceae (15) na área de estudo (padrão observado tanto no componente herbáceo, quanto no lenhoso) (tabela 2) corrobora resultados encontrados em outras áreas do DFC (Araújo et al. 2012, Cordeiro \& Felix 2013, Ferraz et al. 2013, Maracajá et al. 2003, Moro et al. 2014, Pereira Júnior et al. 2012, Oliveira et al. 2009, Rodal et al. 2008). Essas famílias apresentam ampla distribuição e grande número de espécies endêmicas no DFC, principalmente Leguminosae, o que contribui para a maior diversidade e endemismo de espécies na região (Cardoso \& 
Tabela 1. Lista dos levantamentos florísticos (componentes herbáceo e lenhoso) usados nas análises de agrupamento (UPGMA) e ordenação (NMDS). Estados brasileiros - CE: Ceará, PB: Paraíba, PE: Pernambuco, PI: Piauí.

Table 1. List of floristic studies (herbaceous and woody plants sampled) used in the Multivariate Cluster analysis (UPGMA) and Multivariate Ordination analysis (NMDS). Brazilian States - CE: Ceará, PB: Paraíba, PE: Pernambuco, PI: Piauí.

\begin{tabular}{lccc}
\hline Tipo de ambiente & Código do Local & Estado & Referência \\
\hline Caatinga do Cristalino & PB-SJC-Sum & PB & Este estudo \\
Caatinga do Cristalino & CE-Cry1-Cr & CE & Araújo et al. 2011 \\
Caatinga do Cristalino & CE-Cry2-Qu & CE & Costa et al. 2007 \\
Caatinga do Cristalino & PE-Cry17-F & PE & Santos et al. 2009 \\
Caatinga do Cristalino & PE-Cry5-Be & PE & Costa et al. 2009 \\
Caatinga do Sedimentar & CE-Sed1-Cr & CE & Araújo et al. 2011 \\
Caatinga do sedimentar & CE-Sed2-Cr & CE & Araújo et al. 2011 \\
Caatinga do Sedimentar & CE-Sed4-No & CE & Araújo et al. 2011 \\
Caatinga do Sedimentar & PE-Sed1-Bu & PE & Andrade et al. 2004 \\
Caatinga do Sedimentar & PE-Sed2-Bu & PE & Figueiredo et al. 2000 \\
Caatinga do Sedimentar & PE-Sed3-Bu & PE & Gomes et al. 2006 \\
Caatinga do Sedimentar & PE-Sed5-Ib & PE & Rodal et al. 1999 \\
Caatinga do Sedimentar & PI-Sed2-SJ & PI & Mendes et al. 2010 \\
Caatinga do Sedimentar & PI-Sed3-Pa & PI & Oliveira et al. 1997 \\
Caatinga no Agreste & PB-Agr2-La & PB & Lourenço et al. 2003 \\
Caatinga no Agreste & PE-Agr1-Ca & PE & Alcoforado-Filho et al. 2003 \\
Inselberg & PB-Ins3-Pu & PB & Tölke et al. 2011 \\
Inselberg & PE-Ins4-Ve & PE & Gomes et al. 2011 \\
Inselberg & CE-Ins1-Qu & CE & Araújo et al. 2008 \\
Inselberg & PB-Ins2-Es & PB & Porto et al. 2008 \\
Inselberg & PE-Ins1-Be & PE & Gomes \& Alves 2009 \\
Inselberg & PE-Ins2-SJ & PE & Gomes \& Alves 2010 \\
Inselberg & PE-Ins3-Al & PE & Gomes \& Alves 2010 \\
\hline & & &
\end{tabular}

Queiroz 2007, Giulietti \& Queiroz 2006, Queiroz 2006).

Estrutura do componente lenhoso - No hectare estudado foram amostrados 4822 indivíduos lenhosos pertencentes a 34 espécies, com área basal total de $38,851 \mathrm{~m}^{2} \cdot$ ha $^{-1}$ (tabela 4). A altura máxima mensurada foi de $18 \mathrm{~m}$ de altura, observada em um indivíduo de aroeira (Myracrodruon urundeuva Allemão). A altura média da vegetação foi de quatro metros $(\mathrm{s} \pm 2 \mathrm{~m})$. As seis espécies com maior número de indivíduos na área foram Croton heliotropiifolius Kunth (2153), Manihot carthagenensis (Jacq.) Müll. Arg. (530), Bauhinia cheilantha (Bong.) Steud. (466), Combretum glaucocarpum Mart. (432), Mimosa ophthalmocentra Mart. ex Benth. (220) e Croton blanchetianus Baill. (187).

Comparando os dados do presente estudo com outros realizados em áreas de caatinga sensu stricto (terreno cristalino) e caatinga de areia que usaram o mesmo método de amostragem (parcela), tamanho da área (1 ha) e critério de inclusão (PNS $\geq 9 \mathrm{~cm}$ ) (ver tabela 5), foi possível perceber que o componente lenhoso do presente estudo apresenta densidade absoluta (4822 ind. ha ${ }^{-1}$ ) inferior apenas à área estudada por Lemos \& Rodal (2002), no Piauí, e área basal $\left(38,851 \mathrm{~m}^{2}\right.$.ha $\left.\mathrm{h}^{-1}\right)$ superior a todas as outras áreas analisadas. Uma das prováveis razões para a elevada densidade e área basal é o longo período sem perturbações na área de estudo (mais de 50 anos). Embora $C$. blanchetianus e B. cheilantha estejam entre as espécies de maior densidade da área, elas apresentaram baixos valores de área basal pelo menor porte dos indivíduos, enquanto M. urundeuva e Cenostigma bracteosum (Tul.) E. Gagnon \& G.P. Lewis, apesar da baixa densidade, foram dominantes na área estudada pelo maior porte que atingem. As famílias Leguminosae e Euphorbiaceae foram as que apresentaram os maiores IVI, correspondendo a $70 \%$ 
Tabela 2. Lista de espécies do hectare de caatinga estudado na RPPN Fazenda Almas, São José dos Cordeiros (PB). Hábito - Arb: Arbusto, Arv: Árvore, Sub: Subarbusto, Trep: Trepadeira, Erva: Erva. Grau de ameaça - CR: Criticamente Ameaçada, DD: Deficiente de Dados, LC: Menos Preocupante, NE: Não Avaliada, NT: Quase Ameaçada, VU: Vulnerável. Domínio fitogeográficos onde a espécie foi registrada - Am: Amazônia, Ca: Caatinga, Ce: Cerrado, Ma: Mata Atlântica, Pp: Pampa, Pt: Pantanal. Endemismo - Endêmica do Brasil; não endêmica do Brasil; exótica invasora. As informações sobre hábito, origem, grau de ameaça, endemismo e domínios fitogeográficos foram obtidas em http://floradobrasil.jbrj.gov.br/reflora/. Espécies exóticas invasoras estão marcadas na tabela com *.

Table 2. List of species sampled in one-hectare with caatinga vegetation in the RPPN Fazenda Almas, São José dos Cordeiros (Paraíba State), Brazil. Habit - Arb: Shrub, Arv: Tree, Sub: Subhrub, Trep: Climbing plant, Erva: Herb. Degree of threat CR: Critically Endangered, DD: Data Deficient, LC: Least Concern, NE: Not evaluated, NT: Almost Threatened, VU: Vulnerable. Phytogeographical domain - Am: Amazônia, Ca: Caatinga, Ce: Cerrado, Ma: Atlantic Forest, Pp: Pampa, Pt: Pantanal. Endemism: Endemic to Brazil; non-Endemic to Brazil; exotic invasive species. Information about habit, origin, degree of threat, endemism, and phytogeographical domains aswas obtained from http://floradobrasil.jbrj.gov.br/reflora/. Exotic invasive species are tagged with *.

\begin{tabular}{|c|c|c|c|c|c|}
\hline Família/Espécie & Hábito & Grau de ameaça & Endemismo & $\begin{array}{c}\text { Domínios } \\
\text { fitogeográficos }\end{array}$ & $\begin{array}{l}\text { Número de } \\
\text { coletor }\end{array}$ \\
\hline
\end{tabular}

Marchantiophyta

Ricciaceae

Riccia vitalii Jovet-Ast

Lycopodiophyta

Selaginellacea

Selaginella convoluta (Arn.) Spring.

Monilophyta

Anemiaceae

Anemia oblongifolia (Cav.) Sw

Magnoliophyta

Acanthaceae

Dicliptera mucronifolia Nees

Ruellia bahiensis (Nees) Morong

Ruellia geminiflora Kunth

Amaranthaceae

Alternanthera brasiliana (L.) Kuntze

Quaternella ephedroides Pedersen

Anacardiaceae

Myracrodruon urundeuva Allemão

Spondias tuberosa Arruda

Arb/Arv

LC

NE

Não endêmica

Arb/Arv

NE

Não endêmica

$\mathrm{Am}, \mathrm{Ca}, \mathrm{Ce}$, $\mathrm{Ma}$

Barbosa, MR 286

Annonaceae

$$
\begin{aligned}
& \text { Annona leptopetala (R.E.Fr.) H. } \\
& \text { Rainer }
\end{aligned}
$$

Arb/Arv

LC

Endêmica

$\mathrm{Ca}, \mathrm{Ce}$

Silva, RG 27

Apocynaceae

Aspidosperma pyrifolium Mart.
Arv

NE Não endêmica
Am, $\mathrm{Ca}, \mathrm{Ce}$, $\mathrm{Ma}, \mathrm{Pam}, \mathrm{Pa}$

Santos, ND s/n 
Tabela 2 (continuação)

\begin{tabular}{|c|c|c|c|c|c|}
\hline Família/Espécie & Hábito & Grau de ameaça & Endemismo & $\begin{array}{l}\text { Domínios } \\
\text { fitogeográficos }\end{array}$ & $\begin{array}{l}\text { Número de } \\
\text { coletor }\end{array}$ \\
\hline \multicolumn{6}{|l|}{ Araceae } \\
\hline Taccarum peregrinum (Schott) Engl. & Erva & $\mathrm{LC}$ & Não endêmica & $\mathrm{Ca}, \mathrm{Ma}$ & Tomé, MP 123 \\
\hline \multicolumn{6}{|l|}{ Asteraceae } \\
\hline Bidens pilosa L. * & Erva & NE & $\begin{array}{l}\text { Exótica } \\
\text { invasora }\end{array}$ & $\begin{array}{l}\text { Am, Ca, Ce, } \\
\text { Ma, Pam, Pa }\end{array}$ & Tomé, MP 140 \\
\hline Blainvillea acmella (L.) Philipson & Erva & $\mathrm{NE}$ & Não endêmica & $\mathrm{Ca}, \mathrm{Ce}$ & Tomé, MP 136 \\
\hline Delilia biflora (L.) Kuntze & Erva & $\mathrm{NE}$ & Não endêmica & $\mathrm{Ca}, \mathrm{Ce}, \mathrm{Ma}$ & Tomé, MP 45 \\
\hline Melanthera latifolia (Gardner) Cab. & Erva & $\mathrm{LC}$ & Não endêmica & $\begin{array}{l}\mathrm{Am}, \mathrm{Ca}, \mathrm{Ce} \\
\mathrm{Ma}, \mathrm{Pa}\end{array}$ & Tomé, MP 23 \\
\hline Melanthera sp. & Erva & $\mathrm{LC}$ & Não endêmica & $\begin{array}{c}\mathrm{Am}, \mathrm{Ca}, \mathrm{Ce} \\
\mathrm{Ma}, \mathrm{Pa}\end{array}$ & Tomé, MP 155 \\
\hline Porophyllum ruderale (Jacq.) Cass. & Erva & NE & Não endêmica & $\begin{array}{l}\mathrm{Am}, \mathrm{Ca}, \mathrm{Ce} \\
\mathrm{Ma}, \mathrm{Pam}, \mathrm{Pa}\end{array}$ & Tomé, MP 130 \\
\hline Wedelia villosa Gardner & Arb & NE & Desconhecido & $\mathrm{Ca}, \mathrm{Ce}$ & Tomé, MP 51 \\
\hline \multicolumn{6}{|l|}{ Boraginaceae } \\
\hline Heliotropium angiospermum Murray & Erva & $\mathrm{NE}$ & Não endêmica & $\mathrm{Ca}, \mathrm{Ma}$ & Tomé, MP 101 \\
\hline Varronia globosa Jacq. & Sub & $\mathrm{NE}$ & Não endêmica & $\mathrm{Ca}, \mathrm{Ma}$ & Silva, RG 31 \\
\hline $\begin{array}{l}\text { Varronia leucocephala (Moric.) J.S. } \\
\text { Mill. }\end{array}$ & Arb & $\mathrm{NE}$ & Endêmica & $\mathrm{Ca}$ & Silva, RG 14 \\
\hline \multicolumn{6}{|l|}{ Bromeliaceae } \\
\hline $\begin{array}{l}\text { Tillandsia loliacea Mart. ex Schult. \& } \\
\text { Schult.f. }\end{array}$ & Erva & $\mathrm{NE}$ & Não endêmica & $\begin{array}{l}\mathrm{Ca}, \mathrm{Ce}, \mathrm{Ma} \\
\text { Pam, } \mathrm{Pa}\end{array}$ & Silva, RG 14 \\
\hline \multicolumn{6}{|l|}{ Burseraceae } \\
\hline $\begin{array}{l}\text { Commiphora leptophloeos (Mart.) } \\
\text { J.B. Gillett }\end{array}$ & Arb/Arv & $\mathrm{NE}$ & Não endêmica & $\mathrm{Am}, \mathrm{Ca}, \mathrm{Ce}$ & Tomé, MP 153 \\
\hline \multicolumn{6}{|l|}{ Cactaceae } \\
\hline Cereus jamacaru DC. & Arv suculenta & $\mathrm{NE}$ & Endêmica & $\mathrm{Ca}, \mathrm{Ce}$ & Silva, RG 15 \\
\hline $\begin{array}{l}\text { Tacinga inamoena (K. Schum.) N.P. } \\
\text { Taylor \& Stuppy }\end{array}$ & Sub suculenta & DD & Endêmica & $\mathrm{Ca}$ & Pereira, LA 216 \\
\hline \multicolumn{6}{|l|}{ Capparaceae } \\
\hline Cynophalla flexuosa (L.) J. Presl & Arb & NE & Não endêmica & $\begin{array}{l}\mathrm{Am}, \mathrm{Ca}, \mathrm{Ce} \\
\mathrm{Ma}, \mathrm{Pa}\end{array}$ & $\begin{array}{l}\text { Barbosa, MR } \\
2599\end{array}$ \\
\hline \multicolumn{6}{|l|}{ Combretaceae } \\
\hline Combretum glaucocarpum Mart. & Arb/Arv & $\mathrm{NE}$ & Não endêmica & $\begin{array}{l}\mathrm{Am}, \mathrm{Ca}, \mathrm{Ce} \\
\mathrm{Ma}\end{array}$ & $\begin{array}{l}\text { Barbosa, FM } \\
\quad 416\end{array}$ \\
\hline Combretum leprosum Mart. & Arb & NE & Não endêmica & $\begin{array}{l}\mathrm{Am}, \mathrm{Ca}, \mathrm{Ce}, \\
\mathrm{Ma}\end{array}$ & Silva, RG 19 \\
\hline \multicolumn{6}{|l|}{ Commelinaceae } \\
\hline Aneilema brasiliense C.B. Clarke & Erva & $\mathrm{NE}$ & Não endêmica & $\mathrm{Ca}, \mathrm{Ce}, \mathrm{Ma}$ & $\begin{array}{l}\text { Costa, RMT } \\
195\end{array}$ \\
\hline $\begin{array}{l}\text { Callisia filiformis (M. Martens \& } \\
\text { Galeotti) D.R. Hunt }\end{array}$ & Erva & NE & Não endêmica & $\mathrm{Ca}, \mathrm{Ce}$ & Tomé, MP 98 \\
\hline
\end{tabular}


Tabela 2 (continuação)

\begin{tabular}{|c|c|c|c|c|c|}
\hline Família/Espécie & Hábito & Grau de ameaça & Endemismo & $\begin{array}{c}\text { Domínios } \\
\text { fitogeográficos }\end{array}$ & $\begin{array}{l}\text { Número de } \\
\text { coletor }\end{array}$ \\
\hline \multicolumn{6}{|l|}{ Commelinaceae } \\
\hline Commelina erecta $\mathrm{L}$. & Erva & NE & Não endêmica & $\begin{array}{l}\mathrm{Am}, \mathrm{Ca}, \mathrm{Ce} \\
\mathrm{Ma}, \mathrm{Pa}\end{array}$ & Tomé, MP 118 \\
\hline \multicolumn{6}{|l|}{ Convolvulaceae } \\
\hline $\begin{array}{l}\text { Distimake aegyptius (L.) A.R. Simões } \\
\text { \& Staples }\end{array}$ & Trep & NE & Não endêmica & $\begin{array}{l}\mathrm{Am}, \mathrm{Ca}, \mathrm{Ce} \\
\mathrm{Ma}\end{array}$ & Tomé, MP 82 \\
\hline Evolvulus sp. & Erva & & Não endêmica & $\begin{array}{l}\mathrm{Am}, \mathrm{Ca}, \mathrm{Ce} \\
\mathrm{Ma}, \mathrm{Pam}, \mathrm{Pa}\end{array}$ & Tomé, MP 121 \\
\hline $\begin{array}{l}\text { Ipomoea bahiensis Willd. ex Roem. } \\
\text { \& Schult. }\end{array}$ & Trep & NE & Endêmica & $\begin{array}{l}\mathrm{Am}, \mathrm{Ca}, \mathrm{Ce} \\
\mathrm{Ma}\end{array}$ & Tomé, MP 90 \\
\hline Ipomoea brasiliana (Choisy) Meisn. & Trep & $\mathrm{NE}$ & Endêmica & $\mathrm{Ca}, \mathrm{Ce}$ & Tomé, MP 145 \\
\hline Ipomoea nil (L.) Roth * & Trep & NE & $\begin{array}{l}\text { Exótica } \\
\text { invasora }\end{array}$ & $\begin{array}{l}\mathrm{Am}, \mathrm{Ca}, \mathrm{Ce} \\
\mathrm{Ma}\end{array}$ & Tomé, MP 80 \\
\hline Jacquemontia corymbulosa Benth. & Trep & $\mathrm{NE}$ & Não endêmica & $\mathrm{Ca}, \mathrm{Ce}$ & Tomé, MP 132 \\
\hline $\begin{array}{l}\text { Turbina cordata (Choisy) D.F. Austin } \\
\& \text { Staples }\end{array}$ & Trep & $\mathrm{NE}$ & Endêmica & $\begin{array}{l}\mathrm{Am}, \mathrm{Ca}, \mathrm{Ce} \\
\mathrm{Ma}\end{array}$ & Tomé, MP 125 \\
\hline
\end{tabular}

Dioscoreaceae

Dioscorea sp.1 Trep

Dioscorea sp.2 Trep

Não endêmica $\begin{gathered}\text { Am, } \mathrm{Ca}, \mathrm{Ce}, \quad \text { Tomé, MP } 105 \\ \text { Ma, Pam }\end{gathered}$

Não endêmica

Euphorbiaceae

Acalypha multicaulis Müll. Arg.

Erva

NE Não endêmica

Bernardia sidoides (Klotzsch) Mull.

Arg.

Erva NE $\quad$ Endêmica

Cnidoscolus urens (L.) Arthur

Sub

$\mathrm{NE}$

Não endêmica

Croton blanchetianus Baill.

Arb/Arv

Endêmica

Croton heliotropiifolius Kunth

Arb

NE

Não endêmica

Croton hirtus L'Hér

Erva

NE

Croton sp.

LC

Não endêmica

$\mathrm{Am}, \mathrm{Ca}, \mathrm{Ce}$, Ma, Pam

Tomé, MP 103

$\mathrm{Ca}, \mathrm{Ce}, \mathrm{Ma}$,

Tomé, MP 151

$\mathrm{Ca}, \mathrm{Ce}$

Tomé, MP 124

$\mathrm{Am}, \mathrm{Ca}, \mathrm{Ce}$, $\mathrm{Ma}, \mathrm{Pa}$

Tomé, MP 31

$\mathrm{Ca}$

Lima, JR 1012

$\mathrm{Am}, \mathrm{Ca}, \mathrm{Ce}$,

$\mathrm{Am}, \mathrm{Ma}, \mathrm{Ce}$,

Silva, RG 24

$\mathrm{Ma}$
$\mathrm{Ma}$

Tomé, MP 63

Não endêmica

Dalechampia pernambucensis Baill. Trep

NE

$\mathrm{Am}, \mathrm{Ca}, \mathrm{Ce}$,

$\mathrm{Ma}, \mathrm{Pam}, \mathrm{Pa}$

Tomé, MP 156

Endêmica

Dalechampia scandens L.

Trep

NE

$\mathrm{Am}, \mathrm{Ca}, \mathrm{Ma}$

Tomé, MP 157

$\mathrm{Am}, \mathrm{Ca}, \mathrm{Ce}$

$\mathrm{Ma}, \mathrm{Pa}$

Euphorbia comosa Vell.

Erva

NE

Não endêmica

Euphorbia insulana Vell.

Erva

Não ndêmica

$\mathrm{Am}, \mathrm{Ca}, \mathrm{Ce}$,

$\mathrm{Ma}$

Tomé, MP 126

Arbusto

NE

Não endêmica

$\mathrm{Ca}, \mathrm{Ma}$

Tomé, MP 74

Indeterminada

Arb/Arv

NE

Desconhecido

$\mathrm{Am}, \mathrm{Ca}, \mathrm{Ce}$

Tomé, MP 21

Silva, RG 32

Manihot carthagenensis (Jacq.) Müll. Arg.

Arb/Arv

NE

Não endêmica

Am, Ca, Ce Silva, RG 25 
Tabela 2 (continuação)

\begin{tabular}{|c|c|c|c|c|c|}
\hline Família/Espécie & Hábito & Grau de ameaça & Endemismo & $\begin{array}{c}\text { Domínios } \\
\text { fitogeográficos }\end{array}$ & $\begin{array}{l}\text { Número de } \\
\text { coletor }\end{array}$ \\
\hline \multicolumn{6}{|l|}{ Euphorbiaceae } \\
\hline $\begin{array}{l}\text { Microstachys corniculata (Vahl) } \\
\text { Griseb. }\end{array}$ & Sub & $\mathrm{NE}$ & Não endêmica & $\begin{array}{l}\mathrm{Am}, \mathrm{Ca}, \mathrm{Ce} \\
\mathrm{Ma}\end{array}$ & Tomé, MP 38 \\
\hline Sapium glandulosum (L.) Morong & Arb/Arv & NE & Não endêmica & $\begin{array}{l}\mathrm{Am}, \mathrm{Ca}, \mathrm{Ce}, \mathrm{I} \\
\mathrm{Ma}\end{array}$ & $\begin{array}{l}\text { Delgado-Junior, } \\
\text { GC } 49\end{array}$ \\
\hline \multicolumn{6}{|l|}{ Lamiaceae } \\
\hline $\begin{array}{l}\text { Mesosphaerum suaveolens (L.) } \\
\text { Kuntze }\end{array}$ & Erva & $\mathrm{NE}$ & Não endêmica & $\begin{array}{l}\mathrm{Am}, \mathrm{Ca}, \mathrm{Ce} \\
\mathrm{Ma}, \mathrm{Pa}\end{array}$ & Tomé, MP 137 \\
\hline \multicolumn{6}{|l|}{ Leguminosae/Caesalpinioideae } \\
\hline Bauhinia cheilantha (Bong.) Steud. & Arb/Arv & NE & Não endêmica & $\mathrm{Ca}, \mathrm{Ce}$ & Silva, RG 13 \\
\hline $\begin{array}{l}\text { Cenostigma bracteosum (Tul.) E. } \\
\text { Gagnon \& G.P. Lewis }\end{array}$ & Arb/Arv & NE & Endêmica & $\mathrm{Ca}, \mathrm{Ce}$ & Silva, RG 21 \\
\hline $\begin{array}{l}\text { Chamaecrista duckeana (P. Bezerra } \\
\& \text { Afr. Fern.) H.S. Irwin \& Barneby }\end{array}$ & Sub & $\mathrm{NE}$ & Endêmica & $\mathrm{Ca}$ & Tomé, MP 66 \\
\hline $\begin{array}{l}\text { Libidibia ferrea (Mart. ex Tul.) L.P. } \\
\text { Queiroz }\end{array}$ & Arv & $\mathrm{NE}$ & Endêmica & $\mathrm{Ca}, \mathrm{Ce}, \mathrm{Ma}$ & Silva, RG 20 \\
\hline Melanoxylon brauna Schott & Arv & VU & Endêmica & $\mathrm{Ca}, \mathrm{Ce}, \mathrm{Ma}$ & Silva, RG 30 \\
\hline $\begin{array}{l}\text { Senna splendida (Vogel) H.S. Irwin } \\
\text { \& Barneby }\end{array}$ & Arb & $\mathrm{NE}$ & Não endêmica & $\mathrm{Ca}, \mathrm{Ce}, \mathrm{Ma}$ & Silva, RG 22 \\
\hline $\begin{array}{l}\text { Anadenanthera colubrina (Vell.) } \\
\text { Brenan }\end{array}$ & Arb/Arv & $\mathrm{NE}$ & Não endêmica & $\mathrm{Ca}, \mathrm{Ce}, \mathrm{Ma}$ & $\begin{array}{c}\text { Costa, RMT } \\
171\end{array}$ \\
\hline $\begin{array}{l}\text { Chloroleucon foliolosum (Benth.) } \\
\text { G.P. Lewis }\end{array}$ & Arb/Arv & $\mathrm{NE}$ & Não endêmica & $\begin{array}{l}\mathrm{Am}, \mathrm{Ca}, \mathrm{Ce} \\
\mathrm{Ma}\end{array}$ & Silva, RG 18 \\
\hline $\begin{array}{l}\text { Mimosa ophthalmocentra Mart. ex } \\
\text { Benth. }\end{array}$ & Arb/Arv & $\mathrm{NE}$ & Endêmica & $\mathrm{Ca}$ & Silva, RG 11 \\
\hline Piptadenia stipulacea (Benth.) Ducke & Arb & $\mathrm{NE}$ & Endêmica & $\mathrm{Ca}$ & Silva, RG 12 \\
\hline $\begin{array}{l}\text { Amburana cearensis (Allemão) } \\
\text { A.C.Sm. }\end{array}$ & Arv & NT & Não endêmica & $\mathrm{Ca}, \mathrm{Ce}, \mathrm{Ma}, \mathrm{Pa}$ & $\begin{array}{c}\text { Quirino, ZGM } \\
101\end{array}$ \\
\hline $\begin{array}{l}\text { Ancistrotropis peduncularis (Kunth) } \\
\text { A. Delgado }\end{array}$ & Trep & $\mathrm{NE}$ & Não endêmica & $\begin{array}{l}\mathrm{Am}, \mathrm{Ca}, \mathrm{Ce} \\
\mathrm{Ma}, \mathrm{Pa}\end{array}$ & Tomé, MP 110 \\
\hline $\begin{array}{l}\text { Arachis dardani Krapov. \& W.C. } \\
\text { Greg. }\end{array}$ & Erva & $\mathrm{NE}$ & Endêmica & $\mathrm{Ca}, \mathrm{Ce}, \mathrm{Ma}$ & Tomé, MP 128 \\
\hline Centrosema brasilianum (L.) Benth. & Trep & $\mathrm{NE}$ & Não endêmica & $\begin{array}{l}\mathrm{Am}, \mathrm{Ca}, \mathrm{Ce} \\
\mathrm{Ma}, \mathrm{Pa}\end{array}$ & Tomé, MP 50 \\
\hline Desmodium glabrum (Mill.) DC. & Sub & $\mathrm{NE}$ & Não endêmica & $\mathrm{Ca}, \mathrm{Ce}, \mathrm{Ma}$ & Tomé, MP 107 \\
\hline Galactia striata (Jacq.) Urb. & Trep & $\mathrm{LC}$ & Não endêmica & $\begin{array}{l}\mathrm{Am}, \mathrm{Ca}, \mathrm{Ce} \\
\mathrm{Ma}\end{array}$ & Tomé, MP 142 \\
\hline $\begin{array}{l}\text { Luetzelburgia auriculata (Allemão) } \\
\text { Ducke }\end{array}$ & Arv & $\mathrm{NE}$ & Endêmica & $\mathrm{Am}, \mathrm{Ca}, \mathrm{Ce}$ & Silva, RG 16 \\
\hline $\begin{array}{l}\text { Macroptilium martii (Benth.) } \\
\text { Maréchal \& Baudet }\end{array}$ & Trep & NE & Não endêmica & $\mathrm{Ca}, \mathrm{Ma}$ & Tomé, MP 143 \\
\hline
\end{tabular}


Tabela 2 (continuação)

\begin{tabular}{|c|c|c|c|c|c|}
\hline Família/Espécie & Hábito & Grau de ameaça & Endemismo & $\begin{array}{l}\text { Domínios } \\
\text { fitogeográficos }\end{array}$ & $\begin{array}{l}\text { Número de } \\
\text { coletor }\end{array}$ \\
\hline \multicolumn{6}{|l|}{ Lythraceae } \\
\hline Cuphea campestris Koehne & Sub & NE & Não endêmica & $\mathrm{Ca}$ & Tomé, MP 42 \\
\hline \multicolumn{6}{|l|}{ Malvaceae } \\
\hline Ayenia erecta Mart. ex K. Schum. & Erva & NE & Endêmica & $\mathrm{Ca}$ & Tomé, MP 122 \\
\hline Corchorus hirtus L. & Sub & NE & Não endêmica & $\begin{array}{l}\mathrm{Am}, \mathrm{Ca}, \mathrm{Ce} \\
\mathrm{Ma}, \mathrm{Pa}\end{array}$ & Tomé, MP 131 \\
\hline Helicteres muscosa Mart. & Arb & NE & Não endêmica & $\mathrm{Ca}, \mathrm{Ce}$ & Silva, RG 28 \\
\hline Herissantia crispa (L.) Brizicky & Erva & NE & Não endêmica & $\mathrm{Ca}, \mathrm{Ce}$ & Tomé, MP 91 \\
\hline $\begin{array}{l}\text { Herissantia tiubae (K. Schum.) } \\
\text { Brizicky }\end{array}$ & Erva & NE & Endêmica & $\mathrm{Ca}, \mathrm{Ce}$ & Tomé, MP 35 \\
\hline Melochia tomentosa $\mathrm{L}$. & Erva & $\mathrm{NE}$ & Não endêmica & $\mathrm{Ca}, \mathrm{Ce}, \mathrm{Ma}$ & Tomé, MP 158 \\
\hline Pavonia cancellata (L.) Cav. & Erva & NE & Não endêmica & $\begin{array}{l}\mathrm{Am}, \mathrm{Ca}, \mathrm{Ce} \\
\mathrm{Ma}\end{array}$ & Tomé, MP 144 \\
\hline $\begin{array}{l}\text { Pseudobombax marginatum (A.St.- } \\
\text { Hil., Juss \& Cambess) A. Robyns }\end{array}$ & Arv & $\mathrm{LC}$ & Não endêmica & $\mathrm{Ca}, \mathrm{Ce}, \mathrm{Pa}$ & $\begin{array}{l}\text { Vieira, LAF } \\
\quad 121\end{array}$ \\
\hline Sida cordifolia $\mathrm{L}$. & Erva & $\mathrm{NE}$ & Não endêmica & $\begin{array}{l}\mathrm{Am}, \mathrm{Ca}, \mathrm{Ce} \\
\mathrm{Ma}\end{array}$ & Tomé, MP 24 \\
\hline Sida galheirensis Ulbr. & Sub & NE & Endêmica & $\mathrm{Ca}, \mathrm{Ce}, \mathrm{Ma}$ & Tomé, MP 120 \\
\hline Sida procubens $\mathrm{Sw}$. & Sub & $\mathrm{NE}$ & Não endêmica & $\mathrm{Am}, \mathrm{Ca}$ & Tomé, MP 135 \\
\hline Sida rhombifolia L. & Erva & NE & Não endêmica & $\begin{array}{l}\mathrm{Am}, \mathrm{Ca}, \mathrm{Ce} \\
\mathrm{Ma}, \mathrm{Pam}, \mathrm{Pa}\end{array}$ & Tomé, MP 150 \\
\hline Wissadula amplissima (L.) R.E.Fr. & Sub & $\mathrm{NE}$ & Não endêmica & $\mathrm{Ca}, \mathrm{Ce}, \mathrm{Ma}, \mathrm{Pa}$ & Tomé, MP 57 \\
\hline \multicolumn{6}{|l|}{ Nyctaginaceae } \\
\hline Guapira laxa (Netto) Furlan & Arv & NE & Endêmica & $\mathrm{Ca}$ & $\begin{array}{c}\text { Barbosa, FM } \\
330\end{array}$ \\
\hline \multicolumn{6}{|l|}{ Orchidaceae } \\
\hline Cyrtopodium holstii L.C. Menezes & Erva & $\mathrm{LC}$ & Endêmica & $\mathrm{Am}, \mathrm{Ca}, \mathrm{Ma}$ & $\begin{array}{l}\text { Moreira, LHL } \\
09\end{array}$ \\
\hline \multicolumn{6}{|l|}{ Orchidaceae } \\
\hline Sacoila lanceolata (Aubl.) Garay & Erva & $\mathrm{NE}$ & Não endêmica & $\begin{array}{c}\mathrm{Am}, \mathrm{Ca}, \mathrm{Ce} \\
\mathrm{Ma}\end{array}$ & Vieira, LAF 61 \\
\hline $\begin{array}{l}\text { Sarcoglottis grandiflora (Hook.) } \\
\text { Klotzsch }\end{array}$ & Erva & NE & Não endêmica & $\mathrm{Am}, \mathrm{Ce}, \mathrm{Ma}$ & Tomé, MP 149 \\
\hline \multicolumn{6}{|l|}{ Oxalidaceae } \\
\hline Oxalis divaricata Mart. ex Zucc. & Erva & NE & Endêmica & $\begin{array}{l}\mathrm{Am}, \mathrm{Ca}, \mathrm{Ce} \\
\mathrm{Ma}\end{array}$ & Tomé, MP 147 \\
\hline Oxalis glaucescens Norlind. & Erva & $\mathrm{NE}$ & Endêmica & $\mathrm{Ca}, \mathrm{Ce}$ & Tomé, MP 19 \\
\hline \multicolumn{6}{|l|}{ Phyllanthaceae } \\
\hline Phyllanthus heteradenius Mull. Arg. & Erva & NE & Endêmica & $\mathrm{Ca}, \mathrm{Ce}$ & Tomé, MP 129 \\
\hline Phyllanthus tenellus Roxb. & Erva & NE & Não endêmica & $\begin{array}{l}\mathrm{Am}, \mathrm{Ca}, \mathrm{Ce} \\
\mathrm{Ma}\end{array}$ & Tomé, MP 28 \\
\hline
\end{tabular}


Tabela 2 (continuação)

\begin{tabular}{|c|c|c|c|c|c|}
\hline Família/Espécie & Hábito & Grau de ameaça & Endemismo & $\begin{array}{l}\text { Domínios } \\
\text { fitogeográficos }\end{array}$ & $\begin{array}{l}\text { Número de } \\
\text { coletor }\end{array}$ \\
\hline \multicolumn{6}{|l|}{ Poaceae } \\
\hline Melinis repens (Willd.) Zizka * & Erva & NE & $\begin{array}{l}\text { Exótica } \\
\text { invasora }\end{array}$ & $\mathrm{Ca}, \mathrm{Ce}, \mathrm{Ma}$ & Tomé, MP 127 \\
\hline Panicum trichoides Sw. & Erva & NE & Não endêmica & $\begin{array}{l}\mathrm{Am}, \mathrm{Ca}, \mathrm{Ce} \\
\mathrm{Ma}, \mathrm{Pa}\end{array}$ & Tomé, MP 76 \\
\hline Setaria parviflora (Poir.) Kerguélen & Erva & $\mathrm{CR}$ & Não endêmica & $\begin{array}{l}\mathrm{Am}, \mathrm{Ca}, \mathrm{Ce} \\
\quad \mathrm{Ma}, \mathrm{Pa}\end{array}$ & Tomé, MP 52 \\
\hline $\begin{array}{l}\text { Urochloa mollis (Sw.) Morrone \& } \\
\text { Zuloaga * }\end{array}$ & Erva & NE & $\begin{array}{l}\text { Exótica } \\
\text { invasora }\end{array}$ & Am, $\mathrm{Ca}$ & Tomé, MP 49 \\
\hline \multicolumn{6}{|l|}{ Portulacaceae } \\
\hline Portulaca elatior Mart. & Erva & NE & Não endêmica & $\begin{array}{c}\mathrm{Am}, \mathrm{Ca}, \mathrm{Ce} \\
\mathrm{Ma}\end{array}$ & Tomé, MP 146 \\
\hline \multicolumn{6}{|l|}{ Rhamnaceae } \\
\hline Ziziphus joazeiro Mart. & Arv & $\mathrm{NE}$ & Endêmica & $\mathrm{Ca}$ & Costa, RMT 61 \\
\hline \multicolumn{6}{|l|}{ Rubiaceae } \\
\hline $\begin{array}{l}\text { Hexasepalum teres (Walter) J.H. } \\
\text { Kirkbr. }\end{array}$ & Erva & NE & Não endêmica & $\begin{array}{l}\text { Am, } \mathrm{Ca}, \mathrm{Ce} \\
\text { Ma, Pam, Pa }\end{array}$ & Tomé, MP 141 \\
\hline \multicolumn{6}{|l|}{ Sapindaceae } \\
\hline Allophylus quercifolius (Mart.) Radlk. & Arv & NE & Endêmica & $\mathrm{Ca}, \mathrm{Ce}$ & Silva, RG 17 \\
\hline Cardiospermum corindum $\mathrm{L}$. & Trep & $\mathrm{LC}$ & Não endêmica & $\mathrm{Ca}, \mathrm{Ce}, \mathrm{Ma}$ & Tomé, MP 139 \\
\hline Cardiospermum oliveirae Ferruci & Trep & $\mathrm{NE}$ & Endêmica & $\mathrm{Ca}, \mathrm{Ma}$ & Tomé, MP 138 \\
\hline \multicolumn{6}{|l|}{ Solanaceae } \\
\hline Capsicum parvifolium Sendtn. & Arb & NE & Endêmica & $\mathrm{Ca}, \mathrm{Ma}$ & Silva, RG 26 \\
\hline Schwenckia americana Rooyen ex L. & Erva & $\mathrm{NE}$ & Não endêmica & $\begin{array}{c}\mathrm{Am}, \mathrm{Ca}, \mathrm{Ce} \\
\mathrm{Ma}\end{array}$ & Tomé, MP 39 \\
\hline \multicolumn{6}{|l|}{ Turneraceae } \\
\hline Turnera subulata $\mathrm{Sm}$. & Sub & $\mathrm{LC}$ & Não endêmica & $\begin{array}{l}\mathrm{Am}, \mathrm{Ca}, \mathrm{Ce} \\
\mathrm{Ma}\end{array}$ & Tomé, MP 152 \\
\hline \multicolumn{6}{|l|}{ Verbenaceae } \\
\hline Lantana camara $\mathrm{L}$. & Arb & NE & Não endêmica & $\begin{array}{l}\mathrm{Am}, \mathrm{Ca}, \mathrm{Ce} \\
\mathrm{Ma}\end{array}$ & Silva, RG 29 \\
\hline Lippia grata Schauer & Sub & NE & Não endêmica & $\mathrm{Am}, \mathrm{Ca}, \mathrm{Ce}$ & Tomé, MP 119 \\
\hline
\end{tabular}

do IVI total. As espécies com maior IVI, DoAb e DoRe foram C. heliotropiifolius, C. bracteosum e $B$. cheilantha, que somam $57 \%$ do IVI total, $60,5 \%$ da DoAb total e $60,5 \%$ da DoRe total (tabela 4). O H' da área estudada foi de 2,057.

A riqueza de espécies lenhosas encontrada no presente estudo (34) aproximou-se da encontrada em outros estudos fitossociológicos na caatinga, onde poucos superam 40 espécies (ver revisão em Moro et al. 2015), a exemplo de Pereira Júnior et al. (2012), que registraram 37 espécies. Ambos os trabalhos foram realizados na microrregião do Cariri Ocidental, que apresentam características climáticas semelhantes. No entanto, estudos realizados na caatinga de áreas arenosas das bacias sedimentares apresentam riqueza superior a 50 espécies (dentre as quais a bacia sedimentar do Parnaíba e a cuesta da Ibiapaba são algumas das áreas melhor amostradas), como é o caso de Lemos \& Rodal (2002) que registraram 56 espécies no Parque Nacional Serra da Capivara (Piauí). Esta área apresenta precipitação média anual superior à da área de estudo, justificando a maior diversidade 
Tabela 3. Índices de diversidade da flora da área estudada na RPPN Fazenda Almas, São José dos Cordeiros, Estado da Paraíba, Brasil. Riq.: riqueza de espécies, H': índice de diversidade de Shannon-Weaner e $\Delta^{+}$: diversidade taxonômica.

Table 3. Diversity indices of the flora of the studied area in the RPPN Fazenda Almas, São José dos Cordeiros municipality, Paraíba State, Brazil. Riq.: species richness, $H^{\prime}$ : Shannon-Weaner diversity index, and $\Delta^{+}$: taxonomic diversity.

\begin{tabular}{lcc}
\hline Índices & Componente Lenhoso & Componente Herbáceo \\
\hline Riq. & 34 & 80 \\
H'$^{\Delta^{+}}$ & 3,466 & 4,382 \\
\hline
\end{tabular}

Tabela 4. Parâmetros estruturais das espécies lenhosas presentes em um hectare na área de estudo, RPPN Fazenda Almas, São José dos Cordeiros, Estado da Paraíba, Brasil. DAb: Densidade Absoluta (Número de indivíduos/ha), DRe: Densidade Relativa, FAb: Frequência Absoluta, FRe: Frequência Relativa, DoAb: Dominância Absoluta $\left(\mathrm{m}^{2} \cdot \mathrm{ha}^{-1}\right)$, DoRe: Dominância Relativa; IVI: Valor de Importância, IVC: Valor de Cobertura. Os dados brutos de campo podem ser acessados em nosso suplemento digital no link: https://doi.org/10.6084/m9.figshare.8111183.

Table 4. Phytosociological parameters of the woody plant assemblage recorded in one hectare in the study area, RPPN Fazenda Almas, São José dos Cordeiros municipality, Paraíba State, Brazil. DAb: Absolute Density $\left(\mathrm{m}^{2}\right.$.ha $\left.{ }^{-1}\right)$, DRe: Relative Density, FAb: Absolute Frequency, FRe: Relative Frequency, DoAb: Absolute Dominance, DoRe: Relative Dominance, IVI: Value of Importance, IVC: Coverage value. Supplemental raw fieldwork data can be accessed at https://doi.org/10.6084/ m9.figshare.8111183.

\begin{tabular}{lcccccccc}
\hline Espécies & DAb & DRe & FAb & FRe & DoAb & DoRe & IVI & IVC \\
\hline Croton heliotropiifolius Kunth & 2153 & 44,6 & 90 & 9,8 & 14,9 & 38,3 & 92,7 & 82,9 \\
Manihot carthagenensis (Jacq.) Müll. Arg. & 530 & 10,9 & 86 & 9,37 & 1,6 & 4,13 & 24,4 & 15,1 \\
Bauhinia cheilantha (Bong.) Steud. & 466 & 9,65 & 90 & 9,8 & 2,4 & 6,17 & 25,6 & 15,8 \\
Combretum glaucocarpum Mart. & 432 & 9,11 & 76 & 8,28 & 2,38 & 6,13 & 23,5 & 15,2 \\
Mimosa ophthalmocentra Mart. ex Benth. & 220 & 4,55 & 80 & 8,71 & 2,38 & 6,12 & 19,4 & 10,7 \\
Croton blanchetianus Baill. & 187 & 3,87 & 36 & 3,92 & 0,72 & 1,84 & 9,64 & 5,72 \\
Cenostigma bracteosum (Tul.) E. Gagnon \& G.P. Lewis & 165 & 3,44 & 75 & 8,17 & 6,23 & 16 & 27,6 & 19,5 \\
Capsicum parvifolium Sendtn. & 149 & 3,07 & 47 & 5,12 & 0,59 & 1,53 & 9,72 & 4,6 \\
Sapium glandulosum (L.) Morong & 99 & 2,04 & 57 & 6,21 & 0,74 & 1,91 & 10,2 & 3,95 \\
Piptadenia stipulacea (Benth.) Ducke & 63 & 1,32 & 23 & 2,51 & 0,74 & 1,9 & 5,73 & 3,22 \\
Jatropha mollissima (Pohl) Baill. & 60 & 1,24 & 40 & 4,36 & 0,13 & 0,33 & 5,93 & 1,57 \\
Commiphora leptophloeos (Mart.) J. B. Gillett & 57 & 1,17 & 37 & 4,03 & 1,28 & 3,28 & 8,49 & 4,46 \\
Amburana cearensis (Allemão) A.C.Sm. & 48 & 0,99 & 33 & 3,59 & 0,83 & 2,13 & 6,72 & 3,12 \\
Myracrodruon urundeuva Allemão & 45 & 0,93 & 37 & 4,03 & 2,34 & 6,03 & 11 & 6,95 \\
Anadenanthera colubrina (Vell.) Brenan & 33 & 0,7 & 24 & 2,61 & 0,88 & 2,27 & 5,58 & 2,97 \\
Varronia leucocephala (Moric.) J.S. Mill. & 23 & 0,43 & 13 & 1,42 & 0,06 & 0,16 & 2,01 & 0,59 \\
Allophylus quercifolius (Mart.) Radlk. & 13 & 0,33 & 12 & 1,31 & 0,07 & 0,19 & 1,83 & 0,52 \\
Annona leptopetala (R.E.Fr.) H. Rainer & 12 & 0,25 & 9 & 0,98 & 0,04 & 0,09 & 1,32 & 0,34 \\
Combretum leprosum Mart. & 9 & 0,21 & 5 & 0,54 & 0,04 & 0,1 & 0,85 & 0,31 \\
Spondias tuberosa Arruda & 9 & 0,19 & 8 & 0,87 & 0,07 & 0,19 & 1,24 & 0,37 \\
Lantana camara L. & 8 & 0,16 & 8 & 0,87 & 0,02 & 0,05 & 1,08 & 0,21 \\
Aspidosperma pyrifolium Mart. & 7 & 0,14 & 6 & 0,65 & 0,04 & 0,09 & 0,89 & 0,24 \\
Helicteres muscosa Mart. & 7 & 0,14 & 2 & 0,22 & 0,02 & 0,04 & 0,4 & 0,19 \\
Guapira laxa (Netto) Furlan & 6 & 0,12 & 5 & 0,54 & 0,02 & 0,06 & 0,73 & 0,19 \\
Cynophalla flexuosa (L.) J. Presl & 4 & 0,08 & 4 & 0,44 & 0,02 & 0,04 & 0,56 & 0,13 \\
& & & & & & &
\end{tabular}


Tabela 4 (continuação)

\begin{tabular}{lccccccccc}
\hline Espécies & DAb & DRe & FAb & FRe & DoAb & DoRe & IVI & IVC \\
\hline Pseudobombax marginatum (A.St.-Hil., Juss \& Cambess) & 4 & 0,08 & 4 & 0,44 & 0,02 & 0,05 & 0,56 & 0,13 \\
A. Robyns & & & & & & & \\
Melanoxylon brauna Schott & 3 & 0,06 & 2 & 0,22 & 0,21 & 0,55 & 0,83 & 0,61 \\
Chloroleucon foliolosum (Benth.) G.P. Lewis & 2 & 0,04 & 2 & 0,22 & 0,05 & 0,14 & 0,39 & 0,18 \\
Luetzelburgia auriculata (Allemão) Ducke & 2 & 0,02 & 1 & 0,11 & 0 & 0 & 0,13 & 0,02 \\
Varronia globosa Jacq. & 2 & 0,04 & 2 & 0,22 & 0 & 0,01 & 0,27 & 0,05 \\
Indeterminada & 1 & 0,02 & 1 & 0,11 & 0 & 0 & 0,13 & 0,02 \\
Libidibia ferrea (Mart. ex Tul.) L.P. Queiroz & 1 & 0,02 & 1 & 0,11 & 0,04 & 0,11 & 0,24 & 0,13 \\
Senna splendida (Vogel) H.S. Irwin \& Barneby & 1 & 0,02 & 1 & 0,11 & 0 & 0 & 0,13 & 0,02 \\
Ziziphus joazeiro Mart. & 1 & 0,02 & 1 & 0,11 & 0 & 0 & 0,13 & 0,02 \\
Total & 4822 & 100 & 918 & 100 & 38,9 & 100 & 300 & 200 \\
\hline
\end{tabular}

Tabela 5. Densidade, área basal e riqueza de espécies em estudos fitossociológicos em áreas de caatinga no semiárido brasileiro [trabalhos com mesmo método de amostragem (parcelas), área amostral: 1 ha e critério de inclusão (PNS $\geq 9 \mathrm{~cm}$ ) que os do presente estudo].

Table 5. Density, basal area and species richness in phytosociological studies carried out in the caatinga vegetation, Brazilian semiarid [studies with the same sampling method (plot), sampling effort (area size: 1 ha), and inclusion criterion (PNS $\geq 9$ $\mathrm{cm}$ ) used in the present study].

\begin{tabular}{lccccc}
\hline Estado & Localidade & Referência & Densidade & Área Basal & Riqueza \\
\hline PB & Fazenda Almas & Esse estudo & 4822 & 38,851 & 34 \\
PB & Barra de Santa Rosa & Almeida Neto et al. 2009 & 2850 & 12,12 & 22 \\
PB & Monteiro & Pereira Júnior et al. 2012 & 3495 & 28,77 & 37 \\
PE & Brejo da Madre de Deus & Andrade et al. 2009 & 2828 & 19,46 & 32 \\
PE & Floresta; Betânia & Rodal et al. 2008 & 3140 & 18,5 & 28 \\
PI & São Raimundo Nonato & Lemos \& Rodal 2002 & 5655 & 31,9 & 56 \\
\hline
\end{tabular}

encontrada. Além disso, os autores incluíram as lianas em sua amostragem, que foram responsáveis por $14,3 \%$ das espécies encontradas na área (26 espécies). Essas áreas arenosas, especialmente os sítios melhor estudados da Ibiapaba, parecem ser mais ricas em plantas lenhosas do que as áreas sobre terrenos cristalinos e foram identificadas como ecorregiões floristicamente distintas por estudos biogeográficos mais antigos (Araújo et al. 1999, Velloso et al. 2002) e recentes (Moro et al. 2016, Silva \& Souza 2018) e também em nossas análises (ver mais abaixo).

Estrutura do componente herbáceo - Foram registrados 57 espécies, 49 gêneros e 23 famílias (tabela 6) nas duas estações (chuvosa e seca). Foi observada uma variação no número de indivíduos, riqueza de espécies, $\mathrm{H}^{\prime}, \Delta^{+}$e $\%$ de cobertura entre as estações (seca e chuvosa). Na estação chuvosa foram encontrados 4465 indivíduos herbáceos pertencentes a 20 famílias, 43 gêneros e 50 espécies. Nesta estação, $84,5 \%$ do solo estava coberto. Poaceae foi a família com o maior número de indivíduos (1749), seguida por Euphorbiaceae, Oxalidaceae e Selaginellaceae (906, 418 e 413 indivíduos, respectivamente). Feitoza (2013), ao avaliar a variação do componente herbáceo em uma área de caatinga em Pernambuco, afirmou que Poaceae tende a formar populações superabundantes, especialmente em áreas abertas. No entanto, a autora ressalta que esta família, embora abundante no seu estudo, teve sua população reduzida pela metade durante o ano de seca, padrão semelhante ao observado no presente trabalho. As espécies com maior número de indivíduos na estação chuvosa foram: Melinis repens (Willd.) Zizka (1159), uma espécie exótica invasora, Bernardia sidoides (Klotzsch) Mull. Arg. (706) e Urochloa mollis (Sw.) Morrone \& Zuloaga (557), também invasora. $\Delta^{+}$e H' nessa estação foram, respectivamente, 5,049 e 3,932 (tabela 7).

Na estação seca foram encontrados 621 indivíduos herbáceos, pertencentes a 19 famílias, 33 gêneros e 37 espécies. Nesta estação, apenas $32,2 \%$ do solo estava 
Tabela 6. Abundância (número de indivíduos) e porcentagem de cobertura das espécies herbáceas presentes na área de caatinga estudada na RPPN Fazenda Almas, São José dos Cordeiros, Estado da Paraíba (Brasil) nas estações chuvosa e seca. Fl: Espécies presentes apenas no levantamento florístico. * Espécie exótica invasora. A soma das porcentagens de cobertura na estação chuvosa supera $100 \%$ porque várias plantas se sobrepõem verticalmente em uma dada porção da parcela. Os dados brutos de campo podem ser acessados em nosso suplemento digital no link: https://doi.org/10.6084/m9.figshare.8111183.

Table 6. Abundance and cover percentage of herbaceous species present in the caatinga site studied in the RPPN Fazenda Almas, São José dos Cordeiros municipality, Paraíba State (Brazil), in the rainy and dry seasons. Fl: Species present only in the floristic survey. * Exotic Invasive species. The sum of the coverage is above $100 \%$ because during the rainy season many plants grow one over the other. Supplemental raw fieldwork data can be accessed at https://doi.org/10.6084/ m9.figshare.8111183.

\begin{tabular}{lcccc}
\hline Família/Espécie & Abundância & Cobertura & Abundância & Cobertura Seca \\
& Chuvosa & Chuvosa $(\%)$ & Seca & $(\%)$ \\
\hline
\end{tabular}

Acanthaceae

Dicliptera mucronifolia Nees

Ruellia bahiensis (Nees) Morong

Ruellia geminiflora Kunth

Amaranthaceae

Alternanthera brasiliana (L.) Kuntze

Quaternella ephedroides Pedersen

Anemiaceae

Anemia oblongifolia (Cav.) Sw

Araceae

Taccarum peregrinum (Schott) Engl.

Asteraceae

Bidens pilosa $\mathrm{L} . *$

Blainvillea acmella (L.) Philipson

Delilia biflora (L.) Kuntze

Melanthera latifolia (Gardner) Cab.

Melanthera sp.

Porophyllum ruderale (Jacq.) Cass.

Wedelia villosa Gardner

Boraginaceae

Heliotropium angiospermum Murray

Tillandsia loliacea Mart. ex Schult. \& Schult.f.

Cactaceae

Cereus jamacaru DC.

Tacinga inamoena (K. Schum.) N. P. Taylor \& Stuppy

Commelinaceae

Aneilema brasiliense C. B. Clarke

Callisia filiformis (M. Martens \& Galeotti) D.R.Hunt

Commelina erecta $\mathrm{L}$.

Convolvulaceae

Distimake aegyptius (L.) A.R. Simões \& Staples

\section{fl}

0

fl

71

2

1

1

0

0

80

fl

fl

5

21

fl

fl

10

\section{fl}

$3 \quad 0,1$

fl

31

3,0

0

0

0

3

16

0,8

0,7

2,9

16

1,2

fl

fl

0

2

0,1

$\mathrm{fl}$

fl

2

0,3

0

fl

fl

fl

fl

0

38

1,7

3

0,2

0

6

0,6

0 
Tabela 6 (continuação)

\begin{tabular}{lcccc}
\hline Família/Espécie & Abundância & Cobertura & Abundância & Cobertura Seca \\
& Chuvosa & Chuvosa (\%) & Seca & $(\%)$ \\
\hline
\end{tabular}

Convolvulaceae Chuvosa

Seca

(\%)

Evolvulus sp.

Ipomoea bahiensis Willd. ex Roem. \& Schult.

Ipomoea brasiliana (Choisy) Meisn.

Ipomoea nil (L.) Roth*

Jacquemontia corymbulosa Benth.

Turbina cordata (Choisy) D. F. Austin \& Staples

Dioscoreaceae

Dioscorea sp. 1

Dioscorea sp. 2

Euphorbiaceae

Acalypha multicaulis Müll.Arg.

Bernardia sidoides (Klotzsch) Mull.Arg.

Cnidoscolus urens (L.) Arthur

Croton hirtus L'Hér

Croton sp.

Dalechampia pernambucensis Baill.

Dalechampia scandens L.

Euphorbia comosa Vell.

Euphorbia insulana Vell.

Microstachys corniculata (Vahl) Griseb.

Lamiaceae

Mesosphaerum suaveolens (L.) Kuntze

Leguminosae/Caesalpinioideae

Chamaecrista duckeana (P. Bezerra \& Afr. Fern.) H.

S. Irwin \& Barneby

Ancistrotropis peduncularis (Kunth) A. Delgado

Arachis dardani Krapov. \& W.C. Greg.

Centrosema brasilianum (L.) Benth

Desmodium glabrum (Mill.) DC.

Galactia striata (Jacq.) Urb.

Macroptilium martii (Benth.) Maréchal \& Baudet

Lythraceae

Cuphea campestris Koehne

Malvaceae

Ayenia erecta Mart. ex K. Schum.

Corchorus hirtus L.

Herissantia crispa (L.) Brizicky

Herrisantia tiubae K. (Schum.) Brizicky

Melochia tomentosa $\mathrm{L}$.

Pavonia cancellata (L.) Cav.
5

2

4

7

26

12

2

fl

$0,2 \quad 0$

$0,1 \quad 0$

$0,5 \quad 0$

$0,6 \quad 0$

$1,2 \quad 4$

$0,4 \quad 0$

0,2

0

$0,1 \quad 1$

0,1

$\mathrm{fl}$

11

706

fl

117

fl

7

21

fl

9

fl

27

1,0

1,8

19,5

0,8

0,5

3,9

18

20

fl

0

$\mathrm{fl}$

0

0,3

1,1

0,6

0,6

$\mathrm{fl}$

0

fl

11

0,4

7

0,3

0,1

3

2

41

17

179

0,2

0,3

2,7

1,0

1,7

7,6

2,6

30

14

0,6

0

16

0,7

4,3

111

fl

fl
1,3

0,1

0,9

0,8

0,5

3,0

1,0 fl

$\mathrm{fl}$ 
Tabela 6 (continuação)

\begin{tabular}{|c|c|c|c|c|}
\hline Família/Espécie & $\begin{array}{c}\text { Abundância } \\
\text { Chuvosa }\end{array}$ & $\begin{array}{c}\text { Cobertura } \\
\text { Chuvosa (\%) }\end{array}$ & $\begin{array}{l}\text { Abundância } \\
\text { Seca }\end{array}$ & $\begin{array}{c}\text { Cobertura Seca } \\
(\%)\end{array}$ \\
\hline \multicolumn{5}{|l|}{ Malvaceae } \\
\hline Sida cordifolia $\mathrm{L}$. & 14 & 0,5 & 30 & 1,5 \\
\hline Sida galheirensis Ulbr. & 4 & 0,3 & 3 & 0,1 \\
\hline Sida procubens Sw. & 18 & 0,9 & 62 & 2,7 \\
\hline Sida rhombifolia $\mathrm{L}$. & $\mathrm{fl}$ & & $\mathrm{fl}$ & \\
\hline Wissadula amplissima (L.) R. E. Fr. & 13 & 0,9 & 9 & 0,6 \\
\hline \multicolumn{5}{|l|}{ Orchidaceae } \\
\hline Cyrtopodium holstii L. C. Menezes & $\mathrm{fl}$ & & $\mathrm{fl}$ & \\
\hline Sacoila lanceolata (Aubl.) Garay & $\mathrm{fl}$ & & $\mathrm{fl}$ & \\
\hline Sarcoglottis grandiflora (Hook.) Klotzsch & $\mathrm{fl}$ & & $\mathrm{fl}$ & \\
\hline \multicolumn{5}{|l|}{ Oxalidaceae } \\
\hline Oxalis divaricata Mart. ex Zucc. & 361 & 9,2 & 20 & 0,8 \\
\hline Oxalis glaucescens Norlind. & 57 & 2,5 & 3 & 0,2 \\
\hline \multicolumn{5}{|l|}{ Phyllanthaceae } \\
\hline Phyllanthus heteradenius Mull. Arg. & 0 & & 22 & 0,8 \\
\hline Phyllanthus tenellus Roxb. & 20 & 0,7 & 0 & \\
\hline \multicolumn{5}{|l|}{ Poaceae } \\
\hline Melinis repens (Willd.) Zizka* & 1159 & 30,6 & 67 & 3,5 \\
\hline Panicum trichoides Sw. & 57 & 1,4 & 3 & 0,2 \\
\hline Setaria parviflora (Poir.) Kerguélen & $\mathrm{fl}$ & & $\mathrm{fl}$ & \\
\hline Urochloa mollis (Sw.) Morrone \& Zuloaga* & 557 & 20,6 & 1 & 0,1 \\
\hline \multicolumn{5}{|l|}{ Portulacaceae } \\
\hline Portulaca elatior Mart. & 70 & 1,2 & 2 & 0,1 \\
\hline \multicolumn{5}{|l|}{ Ricciaceae } \\
\hline Riccia vitalii Jovet-Ast & $\mathrm{fl}$ & & $\mathrm{fl}$ & \\
\hline \multicolumn{5}{|l|}{ Rubiaceae } \\
\hline Hexasepalum teres (Walter) J.H. Kirkbr. & 19 & 0,2 & 0 & \\
\hline \multicolumn{5}{|l|}{ Sapindaceae } \\
\hline Cardiospermum corindum $\mathrm{L}$. & 16 & 0,9 & 3 & 0,1 \\
\hline Cardiospermum oliveirae Ferruci & 0 & & 4 & 0,2 \\
\hline \multicolumn{5}{|l|}{ Selaginellacea } \\
\hline Selaginella convoluta (Arn.) Spring. & 413 & 16,0 & 90 & 3,5 \\
\hline \multicolumn{5}{|l|}{ Solanaceae } \\
\hline Schwenckia americana Rooyen ex L. & 0 & & 14 & 0,7 \\
\hline \multicolumn{5}{|l|}{ Turneraceae } \\
\hline Turnera subulata $\mathrm{Sm}$. & $\mathrm{fl}$ & & $\mathrm{fl}$ & \\
\hline \multicolumn{5}{|l|}{ Verbenaceae } \\
\hline \multirow[t]{2}{*}{ Lippia grata Schauer } & 0 & & 3 & 0,1 \\
\hline & & 146 & & 33,1 \\
\hline
\end{tabular}


Tabela 7. Índices de diversidade da flora herbácea (Riqueza - riqueza de espécies, $\Delta^{+}$: diversidade taxonômica e H': índice de diversidade de Shannon-Weaner) e parâmetros fitossociológicos (densidade e \% Cobertura do solo) da área estudada na RPPN Fazenda Almas, São José dos Cordeiros, Estado da Paraíba (Brasil), nas estações chuvosa e seca.

Table 7. Index of diversity of herbaceous flora (Richness - species richness, $\Delta^{+}$: taxonomic diversity and $\mathrm{H}^{\prime}$ : diversity index of Shannon-Weaner) and phytosociological parameters (density and \% Coverage of the soil) of the studied area in the RPPN Fazenda Almas, São José dos Cordeiros municipality, Paraíba State (Brazil), in the rainy and dry seasons.

\begin{tabular}{lcc}
\hline & Estação chuvosa & Estação seca \\
\hline Riqueza & 50 & 37 \\
$\Delta^{+}$ & 5,049 & 4,98 \\
$\mathrm{H}$ & 3,932 & 3,664 \\
Densidade & 4465 & 621 \\
\% Cobertura do solo & 84,5 & 32,2 \\
\hline
\end{tabular}

coberto. Malvaceae foi a família com maior número de indivíduos (122), representando $20 \%$ do total de indivíduos encontrados, seguida por Selaginellaceae e Poaceae (90 e 71, respectivamente). As espécies com maior número de indivíduos foram Selaginella convoluta (Arn.) Spring. (90), a exótica Melinis repens (67) e Sida procubens Sw. (56). S. convoluta é considerada uma das poucas licófitas que suportam ambientes xéricos, como a caatinga, pois normalmente plantas desse filo preferem ambientes úmidos e sombreados (Xavier et al. 2012). $\Delta^{+}$e H' nessa estação foram, respectivamente, 4,98 e 3,664 (tabela 7).

Possivelmente, um dos fatores responsáveis pelas diferenças observadas entre os parâmetros analisados foi a maior precipitação na estação chuvosa (tabela 7). Para Andrade et al. (2009), a precipitação influencia algumas populações de plantas, afetando as relações dentro da comunidade, por exemplo, a densidade de indivíduos e cobertura do solo. Outro fator atuante na cobertura do solo é a germinação das sementes presentes no solo. Durante a estação chuvosa, há uma alta germinabilidade do banco de sementes de espécies herbáceas (Silva 2009), o que poderia explicar a maior densidade e cobertura do solo, bem como a maior riqueza de espécies encontrada nesse período.

A diversidade taxonômica da área de estudo diferiu pouco entre as estações (tabela 7), o que pode estar relacionado ao fato de que poucos grupos possuem adaptações que permitem sua sobrevivência em ambientes com sazonalidade climática tão forte. As ordens Fabales e Malvales estão entre as mais diversas da área e tem Leguminosae e Malvaceae como as famílias mais ricas, respectivamente. A família Leguminosae normalmente é citada como uma das mais representativas nos estudos florísticos em caatinga, possivelmente por possuir espécies com adaptações às condições estressantes do ambiente (Andrade et al. 2009). Como já registrado em outras áreas de caatinga do cristalino (Moro et al. 2016), a riqueza de plantas herbáceas superou a de lenhosas.

Vale destacar a presença de espécies exóticas invasoras no componente herbáceo, que são uma ameaça à flora nativa, como Melinis repens, Urochloa mollis e Ipomoea nil (L.) Roth. Em áreas de cerrado, por exemplo, gramíneas invasoras são reconhecidas como um dos grandes problemas para a conservação da biodiversidade (Pivello et al. 1999), e o mesmo deve estar ocorrendo no DFC, embora estudos sobre esse impacto sejam escassos.

Rarefação, extrapolação e estimativa de riqueza total A riqueza observada para o componente lenhoso foi de 34 espécies em 100 parcelas. Os estimadores de riqueza assintótica (figura 2) preveem uma riqueza entre 35 (Chao 2) e 38 (Jack 1) espécies para o local, sugerindo uma amostragem bem próxima da riqueza total local. O método de extrapolação estima que mesmo que o número de parcelas fosse triplicado, apenas duas novas espécies seriam adicionadas à amostragem (figura 3). Assim, a riqueza amostrada no presente estudo parece estar próxima da riqueza real do local, além de estar em linha com o que foi registrado em outras áreas de caatinga do cristalino (Moro et al. 2015), reforçando as conclusões feitas acima sobre a diversidade local moderada no componente lenhoso, quando comparados com vegetações úmidas (a exemplo da Floresta Atlântica - Caiafa \& Martins 2007).

Para o componente herbáceo foi observada uma riqueza de 57 espécies em 70 parcelas (dados da estação seca e chuvosa em conjunto). Os estimadores de riqueza sugerem que a riqueza local deste componente está entre 59 espécies (Chao 2) e 65 


\section{Componente Lenhoso}

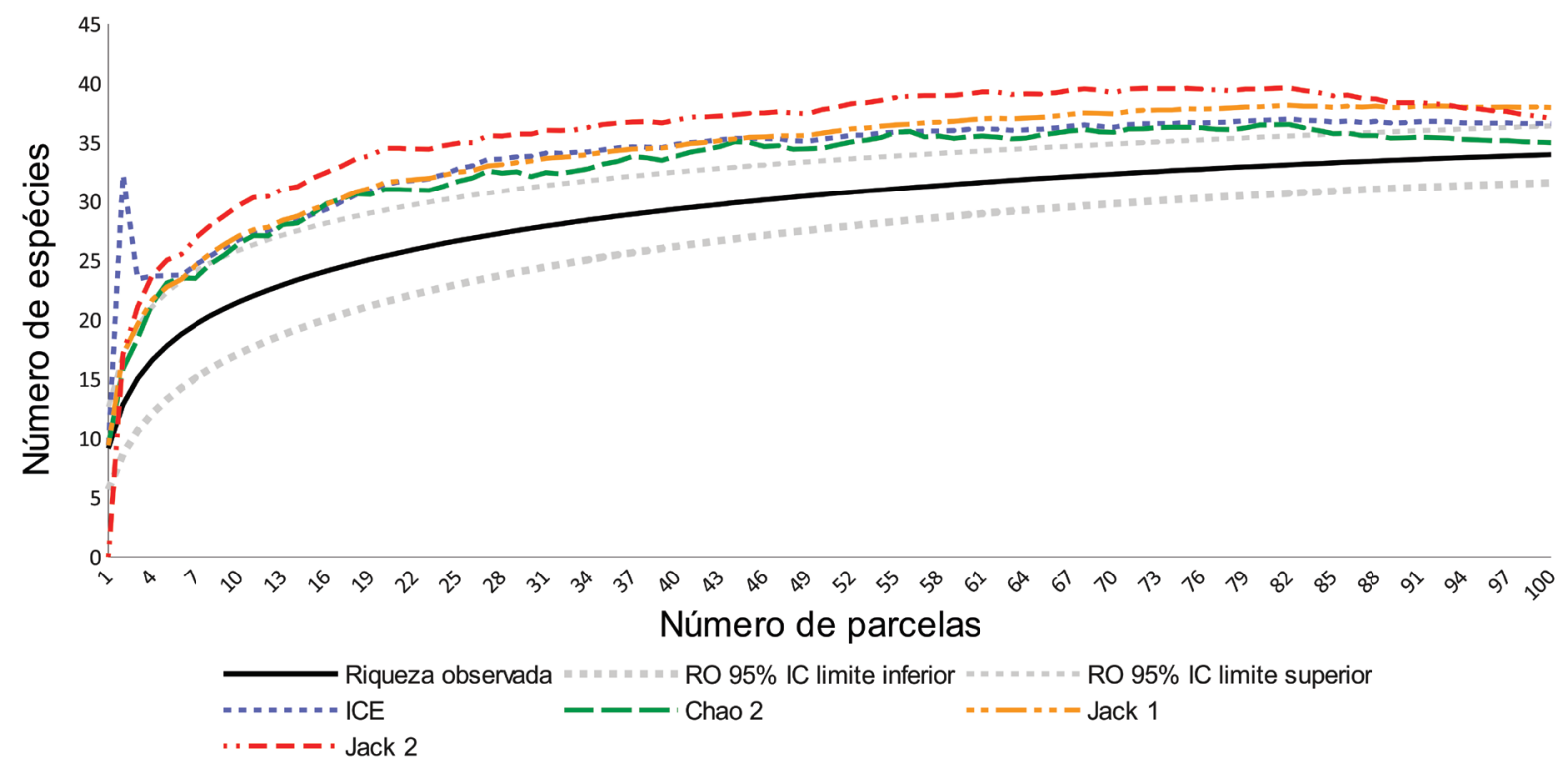

Figura 2. Curva interpolada de acumulação de espécies mostrando o número observado de espécies lenhosas na área de estudo (linha sólida preta) e o número de espécies estimadas por quatro diferentes estimadores de riqueza.

Figure 2. Interpolated curve showing the observed number of woody species in the study area (solid black line) and the number of estimated by four different species richness estimators.

\section{Componente Lenhoso}

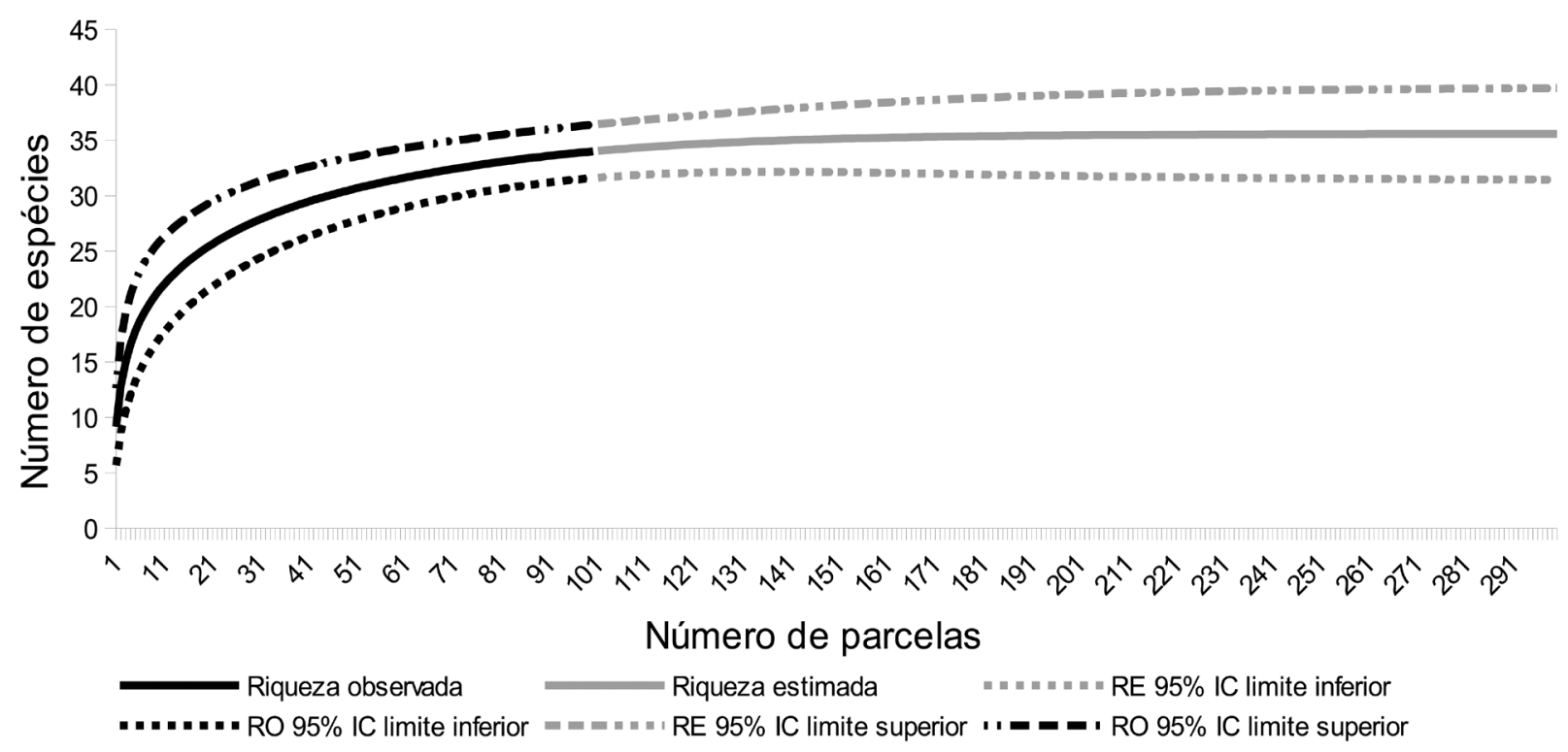

Figura 3. Curva interpolada de acumulação de espécies para a riqueza de plantas lenhosas em 100 parcelas amostradas na área de estudo e curva extrapolada para três vezes além do esforço amostral. RE: riqueza estimada, RO: riqueza observada, IC: intervalo de confiança.

Figure 3. Interpolated curve for the richness of woody species in 100 plots sampled in the study area and extrapolated curve three times beyond the sampling effort. RE: estimated richness, RO: observed richness, IC: confidence interval. 
espécies (Jack 1) (figura 4), demonstrando que esse componente também foi bem amostrado na área de estudo, o que foi confirmado pela curva de coletor extrapolada. Ao analisar a curva extrapolada (figura 5) é possível perceber que o esforço amostral teria que ser triplicado para se conseguir coletar o número de 60 espécies, que representam apenas três espécies a mais. Desta forma, percebe-se que a riqueza local está adequadamente representada pelo estudo.

Contextualização regional - As análises multivariadas de ordenação e agrupamento demonstraram que a flora da área de estudo no Cariri Paraibano possui uma maior similaridade florística com a caatinga que ocorre nos terrenos do cristalino do Estado do Ceará e de Pernambuco (figuras 6 e 7). O DFC é conhecido pela elevada diversidade beta (Apgaua et al. 2014) e aqui foi encontrado um padrão semelhante, com pequena similaridade (distância de Bray-Curtis) entre as áreas. Praticamente todos os sítios apresentaram similaridade menor que 0,5 , mostrando que há reduzida similaridade entre as áreas, reforçando a percepção de que há elevado turnover de espécies no semiárido brasileiro (Apgaua et al. 2014). Entretanto, ao observar a ordenação NDMS e o agrupamento UPGMA (figuras 6 e 7), é possível definir grandes agrupamentos florísticos, ligados tanto ao substrato (cristalino e sedimentar arenoso), quanto aos gradientes climáticos (por exemplo, áreas do agreste, onde chove mais).

De modo geral, foram detectados quatro grupos florísticos: grupo A - formado por uma área mais úmida do agreste, no DFC na Paraíba. Essa área representa um local de maior precipitação dentro do DFC e possui flora consideravelmente diferente das áreas mais secas; grupo B - constituído pelas caatingas presentes na Depressão Sertaneja, grupo onde está inserida a área de estudo, além de dois inselbergs localizados em áreas mais secas e uma área do agreste pernambucano; grupo $\mathrm{C}$ - formado pelas caatingas localizadas nos terrenos arenosos das bacias sedimentares do Parnaíba e de Tucano-Jatobá (correspondentes a duas ecorregiões do DFC conforme mapeadas por Velloso et al. 2002); grupo D - formado pelos inselbegs de áreas mais úmidas, também no agreste da Paraíba e Pernambuco. Desta forma, pode-se afirmar que área de estudo é uma caatinga típica, sendo facilmente diferenciada das áreas de caatinga encontradas nas bacias sedimentares, e apenas parcialmente das áreas do agreste da Paraíba e de Pernambuco, localizadas na transição entre os Domínios Fitogeográficos da Caatinga e da Mata Atlântica.
Os inselbergs são afloramentos rochosos que se destacam na paisagem de diferentes trechos do DFC e de outros Domínios, e fornecem ambientes rupícolas restritivos para algumas espécies, pois, em muitos trechos, os inselbergs têm rochas nuas, nas quais cactáceas, bromeliáceas e outras plantas têm que se fixar em fraturas e irregularidades das rochas. Mas mesmo nos inselbergs, em trehos onde a topografia forma depressões que acumulam solo, esses monólitos abrigam capões de floresta, com composição florística próxima daquela da vegetação do entorno, seja a vegetação da caatinga típica, seja do agreste transicional. Como os inselbergs analisados estão localizados em diferentes setores do semiárido, incluindo trechos mais secos, com flora semelhante à da vegetação de caatinga, e trechos mais úmidos, na transição entre o DFC e a Floresta Atlântica, alguns inselbergs tiveram flora bastante diferenciada, justificando assim o fato desses ambientes não formarem aqui um grupo único e coeso.

Esses grupos são reforçados pelo resultado da ordenação por NMDS (figura 6). Na ordenação, as áreas de caatinga do cristalino aparecem agrupadas com a área de estudo e com dois dos inselbergs. Do mesmo modo, as áreas de terrenos arenosos do sedimentar aparecem próximas entre si, refletindo o padrão observado no UPGMA. Os inselbergs possuem um padrão mais complexo, como já detectado por Moro et al. (2016). Aqueles localizados em áreas mais secas, possuem uma flora próxima da caatinga de áreas cristalinas, ao passo que os inselbergs localizados em áreas mais úmidas do agreste constituem um gradiente florístico na ordenação (figura 6).

Silva \& Souza (2018), usando diferentes análises, identificaram nove sub-regiões biogeográficas para o DFC, concluindo que a flora lenhosa dessa vegetação é espacialmente organizada pela variação da aridez. A RPPN Fazenda Almas, e também as outras áreas do grupo B, estão inseridas na sub-região "São Francisco e Depressão Sertaneja", caracterizada como uma das mais secas do DFC, o que era esperado, uma vez que a RPPN Fazenda Almas está em uma das regiões mais áridas do Nordeste brasileiro. Foi possível ainda observar um agrupamento das áreas que ocorrem em terrenos cristalinos (grupo B) e outro com as áreas que ocorrem em terrenos sedimentares (grupo C), como observado também por Moro et al. (2016) e Lima et al. (2009), embora esse padrão não tenha sido encontrado por Silva \& Souza (2018).

Antongiovanni et al. (2018) mapearam as áreas ao leste do DFC, bem como áreas próximas à divisa 


\section{Componente Herbáceo}

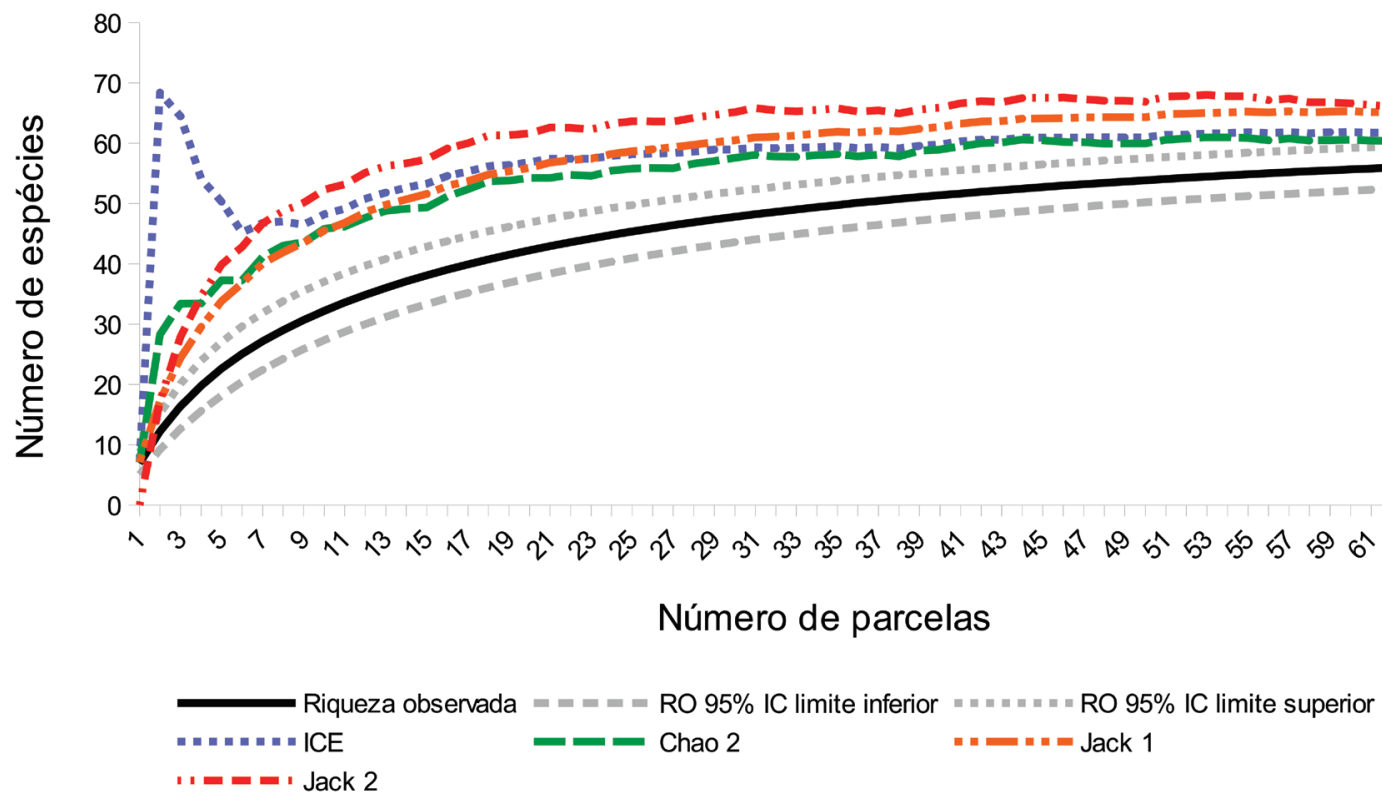

Figura 4. Curva interpolada de acumulação de espécies mostrando o número observado de espécies herbáceas na área de estudo (linha sólida preta) e o número de espécies estimadas por quatro diferentes estimadores de riqueza.

Figure 4. Interpolated curve showing the observed number of herbaceous species in the study area (solid black line) and the number of estimated species by four different species richness estimators.

\section{Componente Herbáceo}

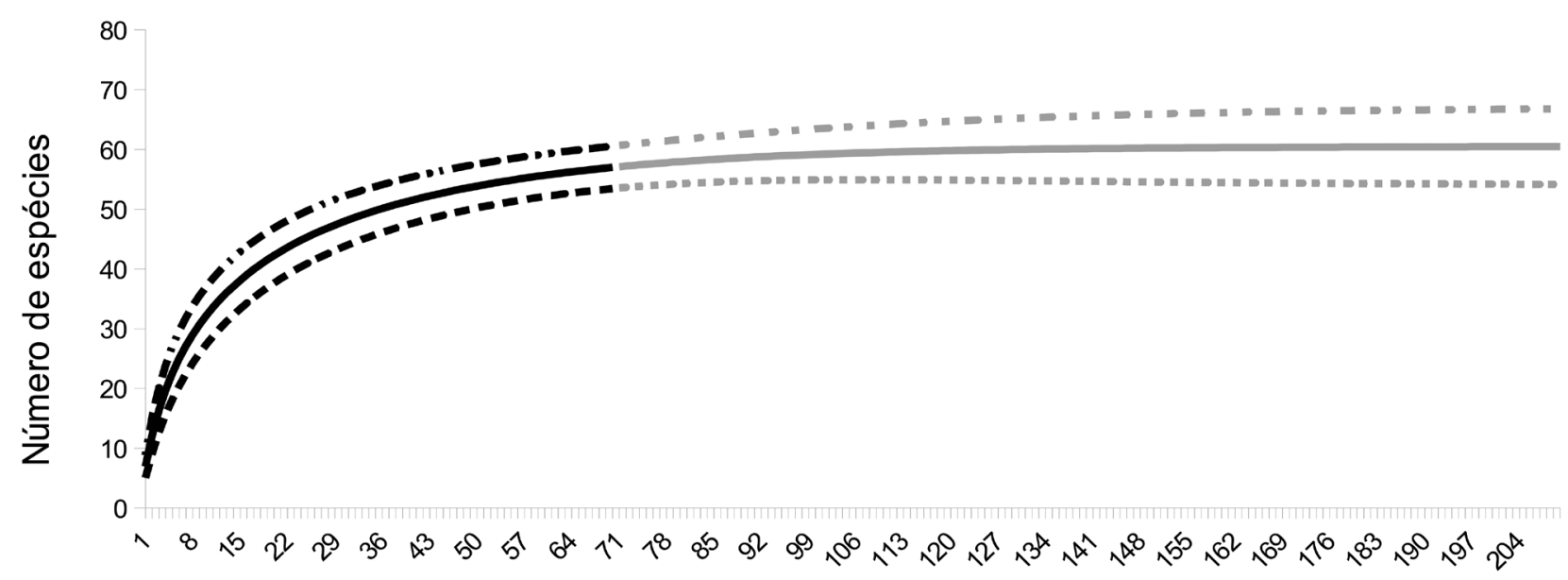

\section{Número de parcelas}

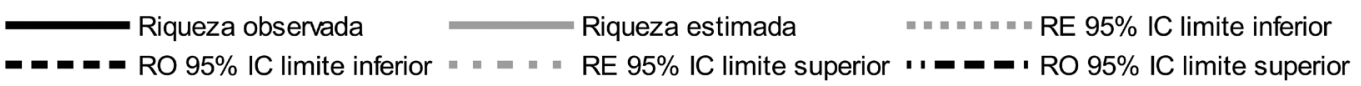

Figura 5. Curva interpolada de acumulação de espécies para a riqueza de plantas herbáceas em 70 parcelas amostradas, e curva extrapolada para três vezes o esforço amostral. RE: riqueza estimada, RO: riqueza observada, IC: intervalo de confiança.

Figure 5. Interpolated curve for the herbaceous species richness in 70 sampled plots, and the curve extrapolated to three times beyond sampling effort. RE: estimated richness, RO: observed richness, IC: confidence interval. 


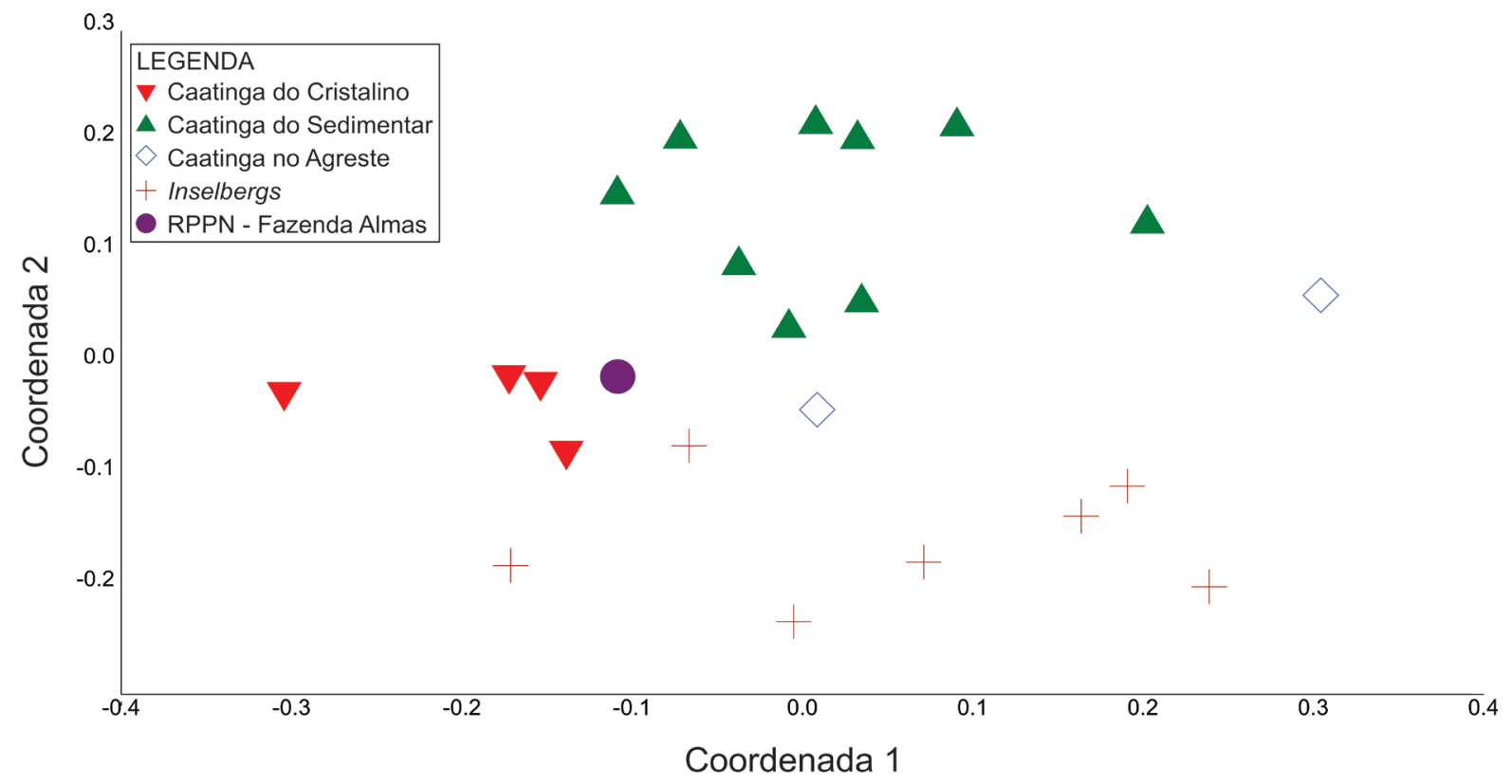

Figura 6. Análise de ordenação (nMDS) para as localidades analisadas, mostrando a relação florística entre as localidades dentro do Domínio Fitogeográfico da Caatinga.

Figure 6. Multivariate ordering analysis (nMDS) for the analyzed localities showing the floristic relationship among the locations within the Phytogeographic Domain of the Caatinga.

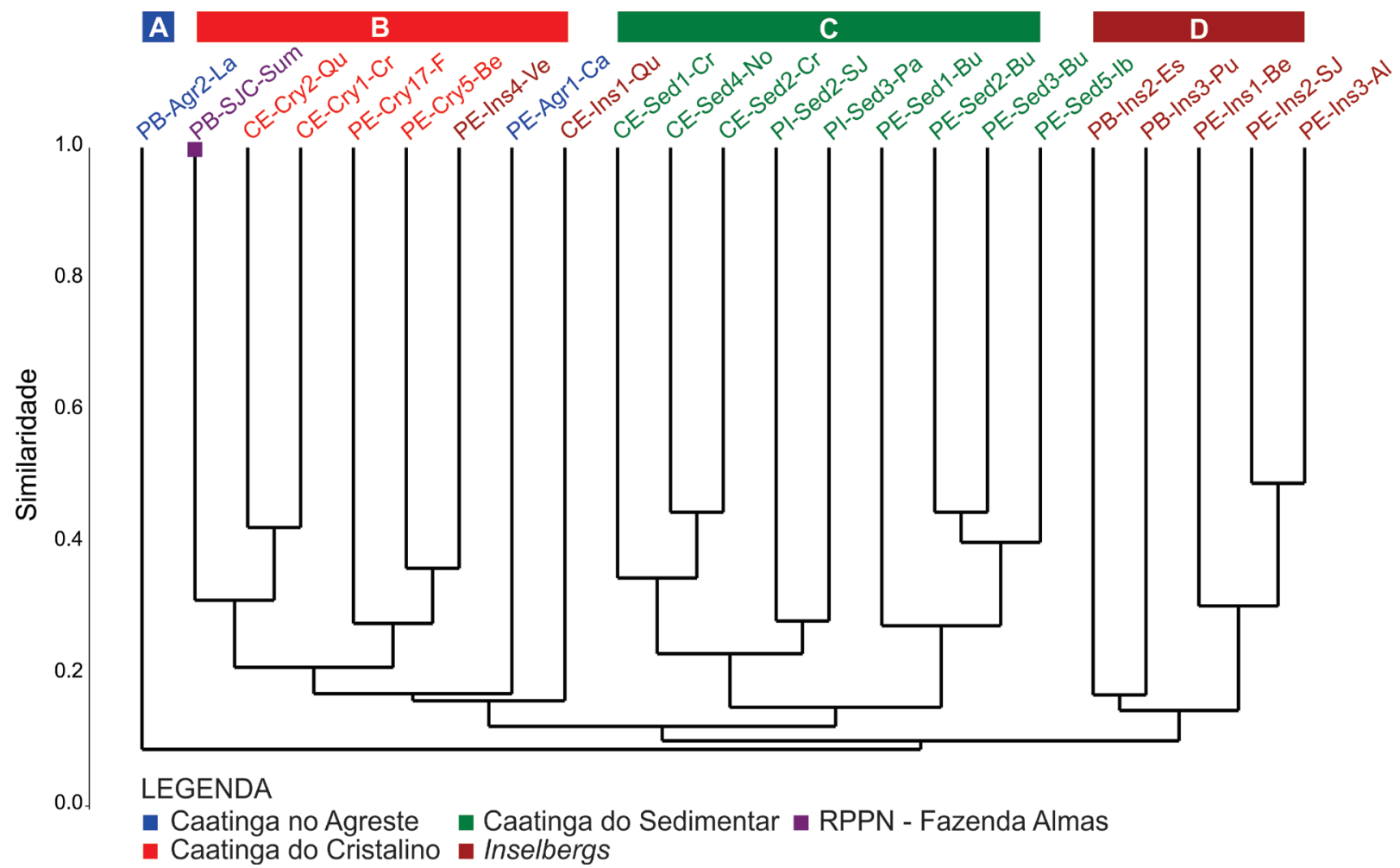

Figura 7. Análise de agrupamento (UPGMA) para os 22 levantamentos selecionados.

Figure 7. Grouping analysis (UPGMA) for the 22 selected surveys. 
entre os Estados da Paraíba e Pernambuco, como sendo áreas com elevado grau de fragmentação. Trabalhos proativos de recuperação ecológica serão necessários nesse setor do DFC (Antongiovanni et al. 2018), mas para que tais projetos sejam adequadamente executados é preciso que se saiba qual a composição florística e estrutura da vegetação em áreas bem conservadas como referência aos projetos de recuperação de áreas. O presente estudo fornece uma contribuição neste sentido, provendo uma lista de espécies nativas e endêmicas, além de dados fitossociológicos da vegetação de caatinga de áreas do cristalino como referências a tais projetos. Mas também é preciso chamar a atenção para o fato de que, dada a heterogeneidade ambiental e da elevada diversidade beta do DFC, um único levantamento não poderá servir como referência para o toda a região. Entretanto, considerando que o presente estudo foi realizado em uma região com paisagens bastante fragmentadas, ele poderá fornecer importantes informações sobre a biodiversidade vegetal de um trecho em bom estado de conservação justamente em uma região que precisará de atenção futura em projetos de recuperação.

\section{Conclusão}

A RPPN Fazenda Almas tem diversidade florística semelhante à de outras áreas de caatinga, estando a maior parte dessa diversidade presente no componente herbáceo. Assim, é possível perceber a importância ecológica das plantas herbáceas para a caatinga e a necessidade de se incluir esse componente em estudos que buscam entender os processos responsáveis por padrões de diversidade, por exemplo. A área de estudo é uma típica caatinga, apresentando maior afinidade florística com áreas de caatinga presente em terrenos do cristalino do estado do Ceará e de Pernambuco. O componente lenhoso apresenta densidade absoluta (4822 ind. ha $\left.{ }^{-1}\right)$ e área basal $\left(38,851 \mathrm{~m}^{2} \cdot \mathrm{ha}^{-1}\right)$, em geral, superior as outras áreas analisadas. $\mathrm{O}$ componente herbáceo apresenta uma variação, principalmente, na densidade absoluta, \% cobertura do solo e riqueza de espécies entre a estação seca e chuvosa.

É importante destacar que pelo menos $50 \%$ do DFC encontra-se alterado pela ação antrópica, e que apesar de sua elevada biodiversidade, ele continua passando por extensos processos de alteração e degradação ambiental. A RPPN estudada está inserida em uma região que apresenta elevado nível de degradação da vegetação natural, o que coloca em risco a manutenção das espécies vegetais e animais ali presentes, algumas das quais já se encontram na lista de espécies ameaçadas de extinção. Isso reforça a importância das RPPNs, que formam uma rede descentralizada de áreas protegidas e que resguardam a biodiversidade vegetal em diversos setores do DFC.

\section{Agradecimentos}

Ao CNPq (Conselho Nacional de Desenvolvimento Científico e Tecnológico) pelo apoio financeiro através do edital Universal 14/2013 (Processo: 471519/2013-8) concedido à primeira autora. Os autores agradecem à Associação Plantas Nordeste (APNE), na pessoa de Roberto Lima, responsável pela RPPN Fazenda Almas e aos auxiliares de campo, em especial ao Srs. Edjane Gonçalves da Silva e Irenaldo da Kosta Brito, pelo apoio e ajuda durante às coletas. À Julieth de Oliveira Sousa pelo auxílio na confecção dos mapas.

\section{Literatura citada}

Ab'Sáber, A.N. 1977. Os domínios morfoclimáticos na América do Sul: primeira aproximação. Geomorfologia 52: $1-22$.

Ab'Sáber, A.N. 2003. Os domínios de natureza no Brasil: potencialidades paisagísticas. Ateliê Editorial, São Paulo.

Alcoforado-Filho, F.G., Sampaio, E.V S.B. \& Rodal, M.J.N. 2003. Florística e fitossociologia de um remanescente de vegetação caducifólia espinhosa arbórea em Caruaru, Pernambuco. Acta Botanica Brasilica 17: 287-303.

Andrade, K.V.S.A., Rodal, M.J.N., Lucena, M.F.A. \& Gomes, A.P.S. 2004. Hoehnea 31: 337-348.

Andrade, L.A., Fabricante, J.R. \& Oliveira, F.X. 2009. Invasão biológica por Prosopis juliflora (Sw.) DC.: impactos sobre a diversidade e a estrutura do componente arbustivo-arbóreo da caatinga no Estado do Rio Grande do Norte, Brasil. Acta Botanica Brasilica 23: 935-943.

Andrade-Lima, D. 1981. The caatingas dominium. Revista Brasileira de Botânica 4: 149-153.

Antongiovanni, M., Venticinque, E.M., \& Fonseca, C.R. 2018. Fragmentation patterns of the Caatinga drylands. Landscape Ecology 33: 1353-1367.

APG IV. 2016. An update of the Angiosperm Phylogeny Group classification for the orders and families of flowering plants: APG IV. Botanical Journal of the Linnean Society. 181: 1-20.

Apgaua, D.M.G., Santos, R.M., Pereira, D.G.S., Menino, G.C.O., Pires, G.G., Fontes, M.A.L. \& Tng, D.Y.P. 2014. Beta-diversity in seasonally dry tropical forests (SDTF) in the Caatinga Biogeographic Domain, Brazil, and its implications for conservation. Biodiversity and Conservation 23: 217-232. 
Araújo, F.S., Martins, F.R., Shepherd, G.J. 1999. Variações estruturais e florísticas do carrasco no planalto da Ibiapaba, estado do Ceará. Revista Brasileira de Biologia 59: 663-678.

Araújo, F.S., Oliveira, R.F. \& Lima-Verde, L.W. 2008. Composição, Espectro Biológico e Síndromes de Dispersão da Vegetação de um Inselbergue no Domínio da Caatinga, Ceará. Rodriguésia 59: 659-671.

Araújo, F.S., Costa, R.C., Lima, J.R., Vasconcelos, S.F., Girão, L.C., Sobrinho, M.S., Bruno, M.M.A., Souza, S.S.G., Nunes, E.P., Figueiredo, M.A., Lima-Verde, L.W. \& Loiola, M.I.B. 2011. Floristics and life-forms along a topographic gradient, central western Ceará, Brazil. Rodriguésia 62: 341-366.

Araújo, K.D., Parente, H.N., Éder-Silva, E., Ramalho, C.I., Dantas, R.T., Andrade, A.P. \& Silva, D.S. 2012. Estrutura fitossociológica do estrato arbustivo-arbóreo em áreas contíguas de caatinga no cariri paraibano. Brazilian Geographical Journal: Geosciences and Humanities research medium 3: 155-169.

Barbosa, M.R.V., Lima, I.B., Lima, J.R., Cunha, J.P., Agra, M.F. \& Thomas, W.W. 2007. Vegetação e flora no Cariri Paraibano. Oecologia brasiliensis 11: 313-322.

Barbosa, M.R.V., Pareyn, F.G.C \& Lima, J.R. 2015. Plano de Manejo - RPPN Fazenda Almas. APNE.

BFG (Brazil Flora Group). 2015. Growing knowledge: an overview of Seed Plant diversity in Brazil. Rodriguésia 66:1085-1113.

Caiafa, A.N. \& Martins, F.R. 2007. Taxonomic Identification, Sampling Methods, and Minimum Size of the Tree Sampled: Implications and Perspectives for Studies in the Brazilian Atlantic Rainforest. Functional Ecosystems and Communities 1: 95-104.

Cardoso, D.B.O.S. \& Queiroz, L.P. 2007. Diversidade de Leguminosae nas caatingas de Tucano, Bahia: implicações para a fitogeografia do Semi-Árido do Nordeste do Brasil. Rodriguésia 58: 379-391.

Castelletti, C.H.M., Santos, A.M.M., Tabarelli, M. \& Silva, J.M.C. 2003. Quanto ainda resta da Caatinga? Uma estimativa preliminar. In: I.R. Leal, M. Tabarelli \& J.M.C. Silva (eds.). Ecologia e conservação da Caatinga. Editora da Universidadeacess Federal de Pernambuco, Recife, pp. 719-734.

Climate-data (Dados climáticos para cidades). 2018. Disponível em https://pt.climate-data.org/(acesso em 02-I-2019).

Colwell, R.K., Elsensohn, J.E. 2014. EstimateS turns 20: Statistical estimation of species richness and shared species from samples, with non-parametric extrapolation. Ecography 37: 609-613.

Colwell, R.K., Chao, A. \& Gotelli, N.J. 2012. Models and estimators linking individual-based and samplebased rarefaction, extrapolation and comparison of assemblages. Journal of Plant Ecology 5: 3-21.
Cordeiro, J.M.P. \& Felix, L.P. 2013. Levantamento fitossociológico em mata de encosta no agreste paraibano. Revista Eletrônica do Curso de Geografia Campus Jataí-UFG 21: 13-28.

Costa, R.C., Araújo, F.S. \& Lima-Verde, L.W. 2007. Flora and life-form spectrum in an area of deciduous thorn woodland (caatinga) in Northeastern, Brazil. Journal of Arid Environments 68: 237-247.

Costa, K.C., Lima, A.L.A., Fernandes, C.H.M., Silva, M.C.N.A., Lins e Silva, A.C.B. \& Rodal, M.J.N. 2009. Flora vascular e formas de vida em um hectare de caatinga no Nordeste brasileiro. Revista Brasileira de Ciências Agrárias 4: 48-54.

Costa, A.C.M., Moro, M.F. \& Martins, F.R. 2016. Raunkiaerian life-forms in the Atlantic forest and comparisons of life-form spectra among Brazilian main biomes. Brazilian Journal of Botany 39: 833-844.

Feitoza, M.O.M. 2013. Variação interanual do componente herbáceo em áreas de caatinga preservada e manejada no sertão pernambucano. Tese de Doutorado, Universidade Federal de Pernambuco, Recife.

Ferraz, R.C., Mello, A.A., Ferreira, R.A. \& Prata, A.P.N. 2013. Levantamento fitossociológico em área de caatinga no monumento natural grota do angico, Sergipe, Brasil. Revista Caatinga 26: 89-98.

Figueiredo, L.S., Rodal, M.J.N. \& Melo, A.L. 2000. Florística e fitossociologia de uma área de vegetação arbustiva caducifólia espinhosa no município de Buíque - Pernambuco. Naturalia 25: 205-224.

Francisco, P.R.M., Ribeiro, G.N, Moraes Neto, J.M. \& Aragão, K.P. 2014. Avaliação da Degradação da Caatinga do Município de Sumé-PB Estimado pelo Volume de Biomassa da Vegetação Lenhosa. Revista Brasileira de Geografia Física 7: 117-129.

Giulietti, A.M., Neta, A.L.B., Castro, A.A.J.F., GamarraRojas, C.F.L., Sampaio, E.V.S., Virgínio, J.F., Queiroz, L.P., Figueiredo, M.A., Rodal, M.J.N., Barbosa, M.R.V. \& Harley, R.M. 2004. Diagnóstico da vegetação nativa do bioma Caatinga. Biodiversidade da Caatinga: áreas e ações prioritárias para a conservação. Ministério do Meio Ambiente, Brasília.

Giulietti, A.M., Conceição, A. \& Queiroz, L.P. 2006. Riqueza de espécies e Caracterização das Fanerógamas do Semi-árido Brasileiro. Recife, Associação Plantas do Nordeste, Ministério da Ciência e Tecnologia.

Gomes, P. \& Alves, M. 2009. Floristic and vegetation aspects of an inselberg in the semi-arid region of northeast Brazil. Edinburgh Journal of Botany 66: 329-346.

Gomes, P. \& Alves, M. 2010. Floristic diversity of two crystalline rocky outcrops in the Brazilian northeast semiarid region. Revista Brasileira de Botânica 33: 661-676.

Gomes, P., Costa, K.C.C., Rodal, M.J.N. \& Alves, M. 2011. Checklist of Angiosperms from the Pedra Furada Municipal Park, northeastern Brazil. Check List 7: 173-181. 
Gomes, A.P.S., Rodal, M.J.N. \& Melo, A.L. 2006. Florística e fitogeografia da vegetação arbustiva subcaducifólia da Chapada de São José, Buíque, PE, Brasil. Acta Botanica Brasilica 20: 37-48.

Gotelli, N.J. \& Colwell, R.K. 2011. Estimating species richness. In: A.E. Magurran \& B.J. McGill (eds.). Biological Diversity Frontiers in Measurement and Assessment. Oxford University Press, Oxford, pp. 39-54.

Hammer, Ø., Harper, D.A.T. \& Ryan, P.D. 2001. Past: paleontological statistics software package for education and data analysis. Palaeontologia Electronica 4: 1-4.

IBGE (Instituto Brasileiro de Geografia e Estatística). 2004. Mapa de biomas do Brasil: primeira aproximação, Rio de Janeiro.

Leal, I.R., Silva, J.M.C, Tabarelli, M. \& Lacher Jr., T.E. 2005. Mudando o curso da conservação da biodiversidade na Caatinga do Nordeste do Brasil. Megadiversidade 1: 139-146.

Legendre, P. \& Legendre, L. 2012. Numerical ecology. Elsevier, Amsterdam.

Lemos, J.R. \& Rodal, M.J.N. 2002. Fitossociologia do componente lenhoso de um trecho de vegetação arbustiva espinhosa no Parque Nacional Serra da Capivara, Piauí, Brasil. Acta Botanica Brasilica 16: 23-42.

Lima, J.R., Sampaio, E.V.S.B., Rodal, M.J.N. \& Araújo, F.S. 2009. Composição florística da floresta estacional decídua montana de Serra das Almas, CE, Brasil. Acta Botanica Brasílica 23: 756-763.

Lima, J.R., Sampaio, E.V.S.B., Rodal, M.J.N. \& Araújo, F.S. 2011. Fisionomia e estrutura de uma floresta estacional decídua no planalto da Ibiapaba, Ceará, Brasil. Rodriguesia 62: 379-389.

Lourenço, C.E.L. \& Barbosa, M.R.V. 2003. Flora da fazenda Ipuarana, Lagoa Seca, Paraíba (Guia de campo). Revista Nordestina de Biologia 17: 23-58.

Magurran, A.E. 2004. Measuring biological diversity. Oxford: Blackwell Publishing.

Maracajá, P.B., Batista, C.H.F., Sousa, A.H. \& Vasconcelos, W.E.L. 2003. Levantamento florístico e fitossociológico do extrato arbustivo-arbóreo de dois ambientes na Vila Santa Catarina, Serra do Mel, RN. Revista de Biologia e Ciências da Terra 3: 25-32.

McCune, B. \& Grace, J.B. 2002. Analysis of ecological communities. MJM Software Design, Gleneden Beach, Oregon.

Mendes, M.R.A. \& Castro, A.A.J.F. 2010. Vascular flora of semi-arid region, São José do Piauí, Brazil. Check List 6: 39-44.

MMA (Ministério do Meio Ambiente). 2002. Biodiversidade Brasileira: Avaliação e Identificação de Áreas Prioritárias para Conservação, Utilização Sustentável e Repartição de Benefícios da Biodiversidade Brasileira. Série Biodiversidade $n^{\circ} 5$. Ministério do Meio Ambiente, Brasília.
MMA (Ministério do Meio Ambiente). 2007. Áreas prioritárias para conservação, uso sustentável e repartição de benefícios da biodiversidade brasileira: atualização: Portaria MMA n ${ }^{\circ}$, de 23 de janeiro de 2007. Série Biodiversidade $n^{\circ} 31$. Ministério do Meio Ambiente, Brasília.

MMA (Ministério do Meio Ambiente). 2010. Uso sustentável e conservação dos recursos florestais da Caatinga. Ministério do Meio Ambiente, Brasília.

MMA (Ministério do Meio Ambiente). 2015. Fifth National Report to the Convention on Biological Diversity: Brazil. Ministério do Meio Ambiente, Brasília.

Moro, M.F., Souza, V.C., Oliveira-Filho, A.T., Queiroz, L.P., Fraga, C.N., Rodal, M.J.N., Araújo, F.S. \& Martins, F.R. 2012. Alienígenas na sala: o que fazer com espécies exóticas em trabalhos de taxonomia, florística e fitossociologia? Acta Botanica Brasilica 26: 991-999.

Moro, M.F., Lughadha, E.N., Filer, D.L., Araújo, F.S. \& Martins, F.R. 2014. A catalogue of the vascular plants of the Caatinga phytogeographical domain: a synthesis of floristic and phytosociological surveys. Phytotaxa 160: 1-118.

Moro, M.F., Araújo, F.S., Rodal, M.J.N. \& Martins, F.R. 2015. Síntese dos estudos florísticos e fitossociológicos realizados no semiárido brasileiro. In: P.V. Eisenlohr, J.M. Felfili, M.M.R.F. Melo, C.A. Andrade \& J.J.A. Meira Neto. Fitossociologia no Brasil: métodos e estudos de casos - Vol. II. Editora da Universidade Federal de Viçosa, Viçosa, pp. 412-451.

Moro, M.F., Lughadha, E.N., Araujo, F.S., \& Martins, F.R. 2016. A phytogeographical metaanalysis of the semiarid Caatinga domain in Brazil. The Botanical Review 82: 91-148.

Nimer, E. 1989. Climatologia do Brasil. Fundação IBGESUPREN, Rio de Janeiro.

Oliveira, J.G.B. \& Sales, M.C.L. 2015. Monitoramento da desertificação em Irauçuba. Imprensa Universitária (UFC), Fortaleza.

Oliveira, M.E.A., Sampaio, E.V.S.B., Castro, A.A.J.F. \& Rodal M.J.N. 1997. Flora e fitossociologia de uma área de transição carrasco-caatinga de areia em Padre Marcos, Piauí. Naturalia 22: 131-150.

Oliveira, P.T.B., Trovão, D.M.B.M., Carvalho, E.C.D., Souza, B.C. \& Ferreira, L.M.R. 2009. Florística e fitossociologia de quatro remanescentes vegetacionais em áreas de serra no cariri paraibano. Revista Caatinga 22: 169-178.

Olson, D.M., Dinerstein, E., Wikramanayake, E.D., Burgess, N.D., Powell, G.V.N., Underwood, E.C., D'amico, J.A., Itoua, I., Strand, H.E., Morrison, J.C., Loucks, C.J., Allnutt, T.F., Ricketts, T.H., Kura, Y., Lamoreux, J.F., Wettengel, W.W., Kassem, Hedao, H. \& Kassem, K.R. 2001. Terrestrial Ecoregions of the World: A New Map of Life on Earth: A new global map of terrestrial ecoregions provides an innovative tool for conserving biodiversity. BioScience 51: 933-938. 
Pereira Júnior, L.R., Andrade, A.P. \& Araújo, K.D. 2012. Composição Florística e Fitossociológica de um fragmento de caatinga em Monteiro-PB. Holos 6: 73-87.

Pivello, V.R., Shida, C.N. \& Meirelles, S.T. 1999. Alien grasses in Brazilian savannas: a threat to the biodiversity. Biodiversity and Conservation 8: 1281-1294.

Porto, P.A.F., Almeida, A., Pessoa, W.J., Trovão, D. \& Félix, L.P. 2008. Composição florística de um inselbergue no agreste paraibano, município de Esperança, Nordeste do Brasil. Revista Caatinga 21: 214-222.

Prado, D. 2003. As caatingas da América do Sul. In: I.R. Leal, M. Tabarelli \& J.M.C. SILVA (eds.). Ecologia e conservação da Caatinga, Ed. Universitária (UFPE), Recife, pp. 3-73.

Queiroz, L.P. 2006. The Brazilian caatinga: phytogeographical patterns inferred from distribution data of the Leguminosae. In: R.T. Pennington, G.P. Lewis \& J.A. Ratter (eds.). Neotropical savannas and dry forests: Plant diversity, biogeography, and conservation. Taylor \& Francis CRC Press, Oxford, pp. 113-149.

Queiroz, R.T., Moro, M.F. \& Loiola, M.I.B. 2015. Evaluating the relative importance of woody versus non-woody plants for alpha-diversity in a semiarid ecosystem in Brazil. Plant Ecology and Evolution. 148: 361-376.

Rizzini, C.T. 1979. Tratado de fitogeografia do Brasil. v. 2. HUCITEC/EDUSP, São Paulo.

Rodal, M.J.N., Sampaio, E.V.S.B. \& Figueiredo, M.A. 1992. Manual sobre métodos de estudo florístico e fitossociológico - ecossistema caatinga. Sociedade Botânica do Brasil, São Paulo.

Rodal, M.J.N., Nascimento, L.M. \& Melo, A.L. 1999. Composição florística de um trecho de vegetação arbustiva caducifólia, no município de Ibimirim, PE, Brasil. Acta Botanica Brasilica 13: 15-28.

Rodal, M.J.N., Martins, F.R. \& Sampaio, E.V.S.B. 2008. Levantamento quantitativo das plantas lenhosas em trechos de vegetação de caatinga em Pernambuco. Revista Caatinga 21: 192-205.

Sampaio, E.V.S.B. 1995. Overview of the Brazilian Caatinga. In: S.H. Bullock, H.A. Mooney \& E. Medina (eds.). Seasonally Dry Tropical Forest Cambridge University Press. Cambridge, pp. 35-63.

Sampaio, E.V.S.B. 1996. Fitossociologia. In: E.V.S.B. Sampaio, S.J. Mayo \& M.R.V. Barbosa (eds.). Pesquisa botânica nordestina: progresso e perspectivas. Recife, Sociedade Botânica do Brasil, pp. 203-224.

Sampaio, E.V.S.B. 2003. Caracterização da caatinga e fatores ambientais que afetam a ecologia das plantas lenhosas. In: V.C. Sales. (org.). Ecossistemas brasileiros: manejo e conservação. Expressão Gráfica e Editora, Fortaleza, pp. 129-142.
Santos, M.F.A.V., Guerra, T.N.F., Sotero, M.C. \& Santos, J.I.N. 2009. Diversidade e densidade de espécies vegetais da Caatinga com diferentes graus de degradação no município de Floresta, Pernambuco, Brasil. Rodriguésia 60: 389-402.

Sherpherd, G.D. FITOPAC 2.1 (versão preliminar). 2010. Universidade Estadual de Campinas, Campinas.

Silva, A.C. \& Souza, A.F. 2018. Aridity drives plant biogeographical sub-regions in the Caatinga, the largest tropical dry forest and woodland block in South America. PLoS ONE 13: 1-22.

Silva, J.M.C. 2003. Introdução. In: J.M.C. Silva, M. Tabarelli, M.T. Fonseca \& L.V. Lins (org.). Biodiversidade da caatinga: áreas e ações prioritárias para a conservação. Ministério do Meio Ambiente, Brasília, pp. 9-10.

Silva, K.A. 2009. Banco de sementes (lenhosas e herbáceas) e dinâmica de quatro populações herbáceas em uma área de caatinga em Pernambuco. Tese de Doutorado, Universidade Federal Rural de Pernambuco, Recife.

SIMRPPN (Sistema Informatizado de Monitoria de RPPN). 2014. Reservas Particulares do Patrimônio Natural - Rppn Fazenda Almas. Disponível em http:// sistemas.icmbio.gov.br/simrppn/publico/detalhe/582/ (acesso em12-IX-2014).

Tabarelli, M. \& Vicente, A. 2002. Lacunas de conhecimento sobre as plantas da Caatinga. In: E.V.S.B. Sampaio, A.M. Giulietti, J. Virgírio \& C.F.L. Gamarra-Rojas (orgs.). Vegetação e flora da Caatinga. Associação Plantas do Nordeste e Centro Nordestino de Informações sobre Plantas. Associação Plantas do Nordeste, Recife, pp. 25-40.

Tabarelli, M. \& Vicente, A. 2004. Conhecimento sobre plantas lenhosas da Caatinga: lacunas geográficas e ecológicas. In: J.M.C. Silva, M. Tabarelli, M.T. Fonseca \& L.V. Lins (orgs.). Biodiversidade da Caatinga: áreas e ações prioritárias para a conservação. Ministério do Meio Ambiente, Brasília, pp. 101-111.

Tölke, E.E.A., Silva, J.B., Pereira, A.R.L. \& Melo, J.I.M. 2011. Flora vascular de um inselbergue no estado da Paraíba, Nordeste do Brasil. Biotemas 24: 39-48.

Velloso, A.L., Sampaio, E.V.S.B. \& Pareyn, F.G.C. 2002. Ecorregiões propostas para o bioma caatinga. Associação Plantas do Nordeste, The Nature Conservancy do Brasil, Recife.

Vieira, R.M.S.P., Tomasella, J, Alvalá, R.C.S., Sestini, M.F., Affonso, A.G., Rodriguez, D.A., Barbosa, A.A., Cunha, A.P.M.A., Valles, G.F., Crepani, E., Oliveira, S.B.P., Souza, M.S.B., Calil, P.M., Carvalho, M.A., Valeriano, D.M., Campello, F.C.B. \& Santana, MO. 2015. Identifying areas susceptible to desertification in the Brazilian northeast. Solid Earth 6: 347-360.

Xavier, S.R.S., Barros, I.C.L. \& Pessôa, A.C.S. 2012. As samambaias e licófitas no semiárido do Brasil. Rodriguésia 63: 483-488. 